\title{
Potential influence of overpressurized gas on the induced seismicity in the St. Gallen deep geothermal project (Switzerland)
}

\author{
Dominik Zbinden, Antonio Pio Rinaldi, Tobias Diehl, and Stefan Wiemer \\ Swiss Seismological Service, ETH Zurich, Switzerland \\ Correspondence: Dominik Zbinden (dominik.zbinden@sed.ethz.ch) \\ Received: 13 October 2019 - Discussion started: 18 November 2019 \\ Revised: 7 April 2020 - Accepted: 16 April 2020 - Published: 20 May 2020
}

\begin{abstract}
In July 2013, the city of St. Gallen conducted a deep geothermal project that aimed to exploit energy for district heating and generating power. A few days after an injection test and two acid stimulations that caused only minor seismicity, a gas kick forced the operators to inject drilling mud to combat the kick. Subsequently, multiple earthquakes were induced on a fault several hundred meters away from the well, including a $M_{\mathrm{L}} 3.5$ event that was felt throughout the nearby population centers. Given the occurrence of a gas kick and a felt seismic sequence with low total injected fluid volumes $\left(\sim 1200 \mathrm{~m}^{3}\right)$, the St. Gallen deep geothermal project represents a particularly interesting case study of induced seismicity. Here, we first present a conceptual model based on seismic, borehole, and seismological data suggesting a hydraulic connection between the well and the fault. The overpressurized gas, which is assumed to be initially sealed by the fault, may have been released due to the stimulations before entering the well via the hydraulic connection. We test this hypothesis with a numerical model calibrated against the borehole pressure of the injection test. We successfully reproduce the gas kick and spatiotemporal characteristics of the main seismicity sequence following the well control operation. The results indicate that the gas may have destabilized the fault during and after the injection operations and could have enhanced the resulting seismicity. This study may have implications for future deep hydrothermal projects conducted in similar geological conditions with potentially overpressurized in-place gas.
\end{abstract}

\section{Introduction}

Industrial injection and extraction projects causing anthropogenic earthquakes have increased during recent years and have been conducted closer to densely populated areas (Foulger et al., 2018). As a result, both the nonscientific and scientific community's interest in induced seismicity has risen dramatically. Anthropogenic earthquakes have been observed related to water impoundment, mining, geothermal power production, hydrocarbon extraction, hydraulic fracturing for shale gas extraction, $\mathrm{CO}_{2}$ sequestration, wastewater injection, and cyclic injection and extraction operations at underground gas storage (UGS) sites (Ellsworth, 2013; Grigoli et al., 2017; Foulger et al., 2018). Industrial and societal problems arising from induced seismicity are 2-fold. On the one hand, large induced seismic events can be a risk to the population and cause damage to structures. For instance, in the United States mid-continent, several $M>5$ events have been recorded after wastewater injection, causing substantial damage to structures and harm to people (Yeck et al., 2017). On the other hand, geo-energy projects may be jeopardized by lack of public support due to felt but only slightly damaging seismic events. A striking example is the Enhanced Geothermal System (EGS) project in Basel, Switzerland, where seismicity was induced immediately below the city, which led to the suspension of the entire project (e.g., Giardini, 2009). Recent history clearly shows that the success of geo-energy, in particular geothermal projects, largely depends on the level at which we are able to control induced seismicity (Kraft et al., 2009; Kwiatek et al., 2019). There is an urgent need to communicate transparently with the public and employ methods that will safely keep the seismicity to a tolerable level (Giardini, 2009; Lee et al., 2019). Understanding the physics behind the induced seismicity is an important 
step necessary to assess the hazard and risk of geo-energy projects and to develop methods to mitigate the seismicity. Hence, it is crucial to get a more accurate understanding of the thermo-hydromechanical-chemical interactions occurring at reservoir depths.

To date, two main mechanisms are thought to be responsible for man-made earthquakes: (i) removing or adding mass (e.g., mining, water impoundment) and (ii) injection or withdrawal of fluid (e.g., geothermal power, hydrocarbon extraction, wastewater injection, and $\mathrm{CO}_{2}$ sequestration; Foulger et al., 2018). For injection or extraction activities, pressure and temperature changes influence the state of stress in the subsurface zones. This process is considered to be the main mechanism employed in deep geothermal projects, where cold water injection and hot water or steam production can change the effective stress in and around the reservoir and hence induce earthquakes. Several geothermal projects globally have induced seismicity (e.g., Baisch et al., 2015; Evans et al., 2012; Grigoli et al., 2018; Jeanne et al., 2015); recently, a $M_{\mathrm{w}} 5.5$ earthquake struck the city of Pohang (South Korea) (Ellsworth et al., 2019; Grigoli et al., 2018), the largest earthquake recorded at an EGS site to date (Kim et al., 2018). This earthquake has challenged recently proposed models that relate the maximum expected seismic magnitude to the total injected fluid volume (Galis et al., 2017; McGarr, 2014). In contrast to the majority of geo-energy projects conducted so far, the main shock in Pohang lies well beyond the magnitude threshold given by such models.

The deep geothermal project in St. Gallen conducted in 2013 shows some similarity with the Pohang event, given the relatively strong induced seismicity (in terms of total released seismic moment) after the injection of rather small volumes of fluid. A few days after an injection test and two acid stimulations that caused only minor seismicity, gas entered the borehole from an unidentified source at a pressure greater than the one exerted by the fluid column in the borehole (a so-called gas kick). The gas kick was fought by pumping fresh water and heavier drilling mud into the well (e.g., Moeck et al., 2015). The well control injection induced multiple seismic events (Fig. 1), including a local magnitude $M_{\mathrm{L}} 3.5$ (moment magnitude $M_{\mathrm{w}} 3.3$; Diehl et al., 2014) earthquake that was distinctly felt throughout the population centers adjacent to the well (e.g., Edwards et al., 2015). For St. Gallen, using McGarr's model (McGarr, 2014) that relates the maximum expected magnitude $M_{\max }$ to the product of the shear modulus $G$ (30 GPa following McGarr, 2014) and the total injected volume $V$ (ca. $1200 \mathrm{~m}^{3}$ neglecting additional mud losses; Alber and Backers, 2015, and references therein), gives a $M_{\max }$ of 3.0. Despite the assumption of a relatively stiff fault, the main event $\left(M_{\mathrm{w}} 3.3\right)$ is above the theoretically derived threshold. This calls for a more thorough analysis of the hydromechanical processes taking into account multiphase fluid flow to evaluate the potential influence of the gas. Since we only have a limited knowledge of the deep subsurface (e.g., from boreholes and nondestructive geophysical methods), numerical modeling can help shed light on otherwise hidden processes.

In this study, we perform hydromechanical simulations to more accurately understand the causes of the induced seismicity during the St. Gallen deep geothermal project. Our aim is to propose and evaluate potential mechanisms that led to the seismicity and to reproduce the characteristics of the main sequence in July 2013 (denoted as phase A in Fig. 1a). Firstly, we describe the temporal and spatial evolution of the seismic sequence associated with the injection. Secondly, we present a conceptual model for the induced seismicity in St. Gallen based on the earthquake catalog (Diehl et al., 2017), data from a 3D seismic campaign (Heuberger et al., 2016), and data from the borehole St. Gallen (SG) GT-1 (Wolfgramm et al., 2015). We then present a 3D numerical model using TOUGH2-seed (Rinaldi and Nespoli, 2017) that combines the multicomponent and multiphase fluid flow simulator TOUGH2 (Pruess et al., 2012) with a geomechanicalstochastic model (Catalli et al., 2016; Gischig and Wiemer, 2013; Gischig et al., 2014; Goertz-Allmann and Wiemer, 2013). Our model is calibrated to the well pressure response during the injection test and the gas kick. We simulate the injection test, the gas kick, and the well control injection to reproduce the main seismic sequence at the end of July 2013. In our simulations, the primary focus is the potential effect of gas on the induced seismicity. Finally, we discuss our results in the context of future deep hydrothermal projects.

\section{The deep geothermal project in St. Gallen}

The St. Gallen deep geothermal project was conducted in the North Alpine Foreland Basin a few kilometers west of the city of St. Gallen (Fig. 2). The plan was to drill into the fractured damage zone within the St. Gallen Fault Zone (SFZ), a $20 \mathrm{~km}$ long fault system consisting of several steeply dipping normal and subsidiary apparent reverse faults striking NNESSW (Heuberger et al., 2016). The target formation was chosen to be the Malm carbonate layer (Upper Jurassic, top of the Mesozoic sediments at this site) located in the damage zone of two normal faults of the SFZ at a depth of about $4 \mathrm{~km}$. The formation was expected to be sufficiently permeable to circulate water at rate of at least $50 \mathrm{~L} \mathrm{~s}^{-1}$ (e.g., Hirschberg et al., 2015) per $200 \mathrm{~m}$ of drawdown in the well ( $\sim 2 \mathrm{MPa}$; Thomas Bloch, personal communication, 7 September 2019) without requiring permeability enhancement by EGS-type hydraulic stimulation. Although the St. Gallen deep geothermal project has been considered an EGS in some studies (e.g., Breede et al., 2013), we here clearly classify it as a hydrothermal project, since no hydraulic stimulation for the targeted shearing of fractures (hydro-shearing) was performed adjacent to the injection well (see below). The choice of the reservoir was motivated by the fact that at different sites in southeastern Germany, multiple hydrothermal systems are currently running successfully in similar geological condi- 

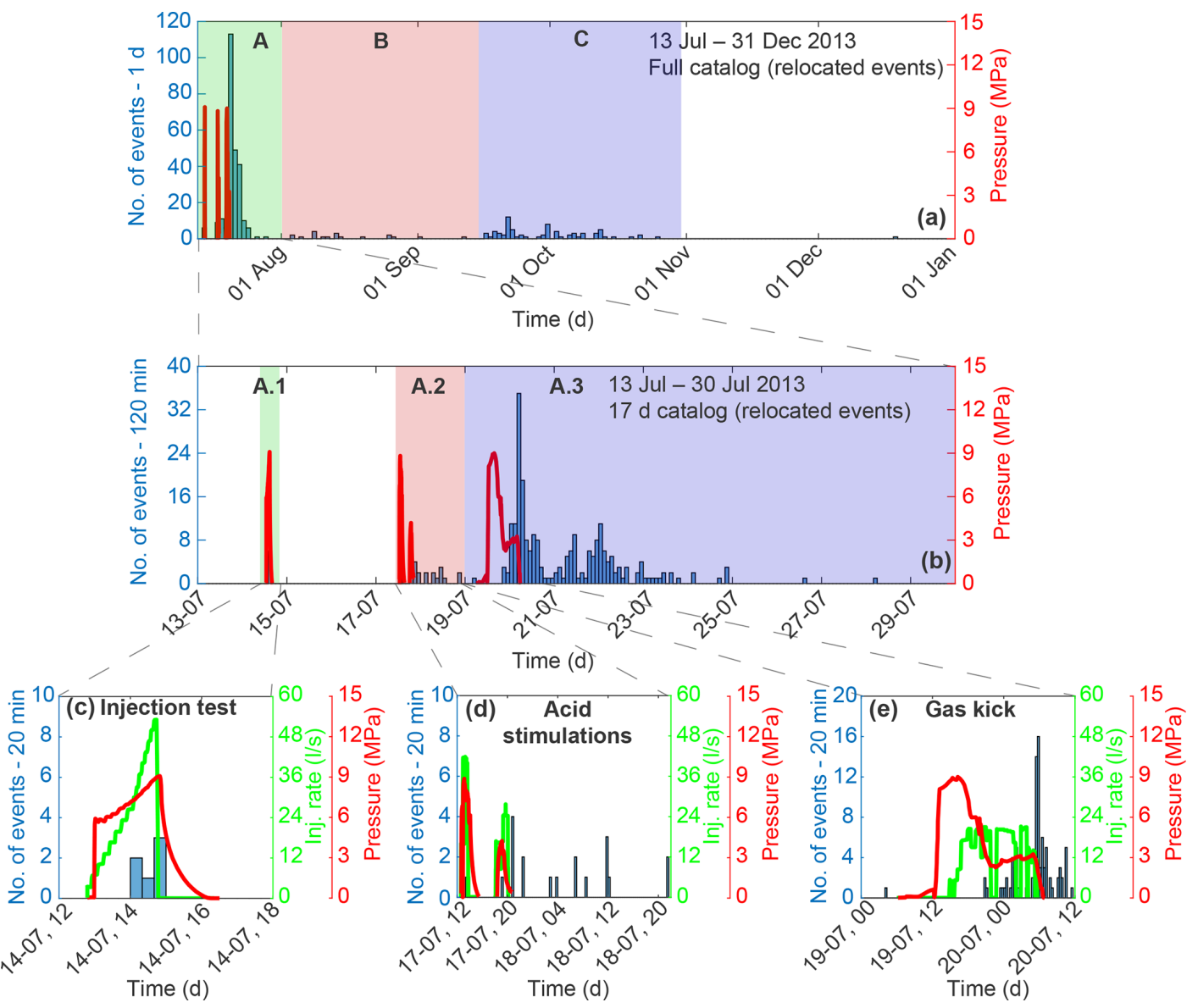

Figure 1. The St. Gallen induced seismicity sequence: (a) time series of the wellhead pressure in SG GT-1 and number of relocated events of the full catalog from July to the end of 2013. A: main seismicity sequence; B: more quiet post-injection period; C: seismic activity restarts due to cleaning and fishing operations. (b) Time series of the wellhead pressure in SG GT-1 and number of relocated events from 13 July to the end of July 2013. A.1: injection test; A.2: acid stimulations; A.3: gas kick and well control measures. (c, d, e) Time series of the injection rates and wellhead pressure in SG GT-1, as well as the number of relocated seismic events for the (c) injection test (14 July), (d) acid stimulations (17 July), and gas kick including the well control injection (19-20 July). The full relocated catalog is taken from Diehl et al. (2017).

tions (Wolfgramm et al., 2015). A 3D seismic survey carried out between 2009 and 2010 revealed that the SFZ tapers off in the crystalline basement, probably bounding a PermoCarboniferous trough (PCT) below the Mesozoic sediments (Heuberger et al., 2016). The PCT is poorly defined in the seismic survey, since strong reflections from the sediments above prevented a detailed interpretation of the deeper horizons (Heuberger et al., 2016).

The St. Gallen region had experienced only minor natural seismicity prior to the project, with the largest being a $M_{\mathrm{L}} 3.2$ earthquake since 1984 (Diehl et al., 2017). Only two historic earthquakes with $M_{\mathrm{W}}>4.0$ were reported in the vicinity of the geothermal site (Fäh et al., 2011). Nevertheless, in anticipation of a possible induced microseismic activity, the regional seismic network was densified locally at the beginning of 2012 with a short-period borehole sensor and five broadband surface stations within a radius of $12 \mathrm{~km}$ around the geothermal well. During the stimulation phase in July 2013, the network was further extended by seven short-period surface stations (Diehl et al., 2017; Edwards et al., 2015).

In the beginning of July 2013, the drilling of the SG GT-1 well was completed to a true vertical depth (TVD) of about $4.2 \mathrm{~km}$ without inducing any seismic events (depth is defined relative to the top of the borehole throughout the paper). The open section extended from 3.8 to $4.2 \mathrm{~km}$ TVD within the Malm formation. In order to get an estimate of the hydraulic properties of the reservoir, an injection test was performed on 14 July (phase A.1 in Fig. 1b and Fig. 1c). Water was injected with a stepwise increasing rate reaching a maximum of $53 \mathrm{~L} \mathrm{~s}^{-1}$. A total of $175 \mathrm{~m}^{3}$ of water was pumped into the subsurface, leading to a pressure increase from 36.7 to $46.5 \mathrm{MPa}(\Delta P=9.8 \mathrm{MPa})$ and inducing some microearthquakes with six being precisely located (Diehl et al., 2017). These were the first seismic events recorded 


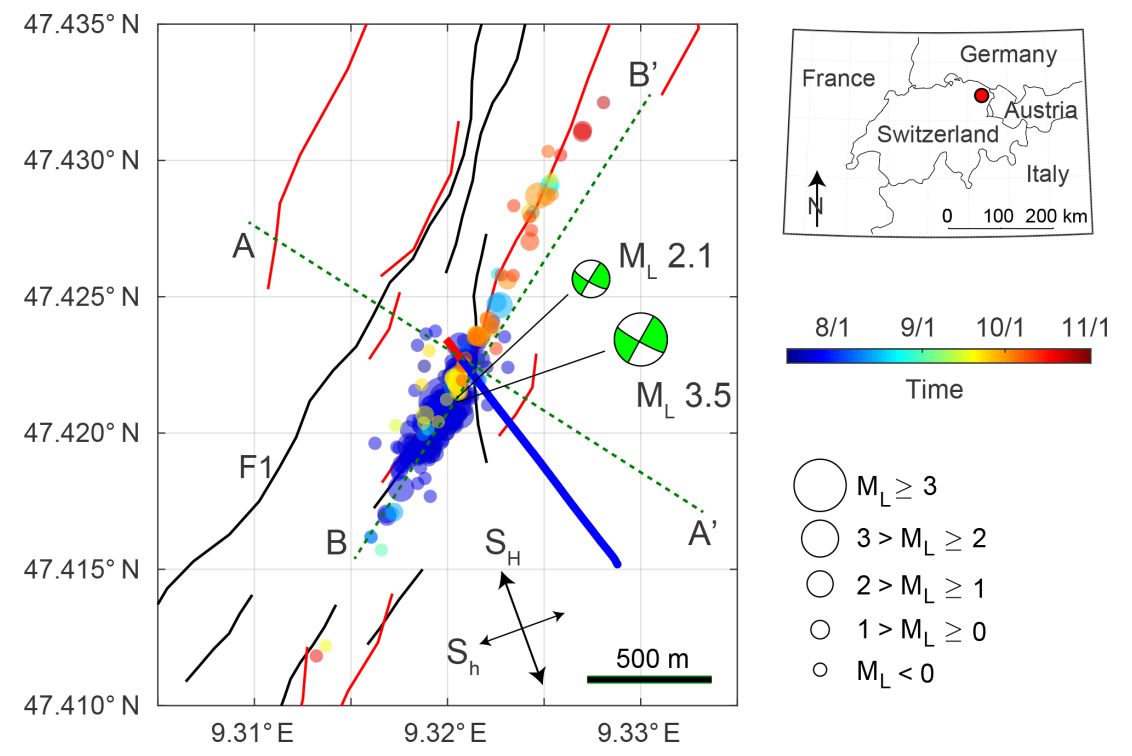

Figure 2. Map view of the relocated events color-coded by origin time (format month/day). The fault plane solutions of the $\mathrm{M}_{\mathrm{L}} 3.5$ and $\mathrm{M}_{\mathrm{L}} 2.1$ events (Diehl et al., 2017) are denoted by the green focal mechanisms. Red (top Malm) and black (bottom Muschelkalk) lines illustrate the faults of the SFZ including a large fault (F1) bounding the Permo-Carboniferous trough (Heuberger et al., 2016). The cased and open section of borehole GT-1 are denoted by the thick blue and red lines, respectively. The black arrows sketch the orientation of the minimum and maximum principal stress after Moeck et al. (2015). The red dot in the European map (top right) marks the location of the St. Gallen deep geothermal project.

since microseismic monitoring began in 2012. On 17 July, two acid stimulations were performed in sections where permeable fractures were expected, and a total of $150 \mathrm{~m}^{3}$ hydrochloric acid and $140 \mathrm{~m}^{3}$ of water was injected (phase A.2 in Fig. $1 \mathrm{~b}$ and Fig. 1d). The first acid stimulation was conducted in the Lower Malm at a depth of $4.15 \mathrm{~km}$, reaching maximum injection rates of $42 \mathrm{~L} \mathrm{~s}^{-1}$ and a wellhead pressure increase of $8.8 \mathrm{MPa}$. The second acid stimulation was performed in the Upper Malm with injection rates of up to $24 \mathrm{~L} \mathrm{~s}^{-1}$ and a pressure increase of up to $6.3 \mathrm{MPa}$. During the first acid stimulation, only a few microearthquakes with $M_{\mathrm{L}}<0.0$ were recorded, two of them being relocated at a depth of approx. $4.9 \mathrm{~km}$. The second acid stimulation led to much more seismicity; 19 microearthquakes with $M_{\mathrm{L}}<0.5$ were relocated until the morning of 19 July at an average depth of ca. $4.6 \mathrm{~km}$ (Diehl et al., 2017), i.e., shallower than the microevents during the first acid stimulation. The number and magnitude of the seismic events was well within the range expected for the injected fluid volumes. On 19 July at noon, gas (roughly $90 \%$ methane; Wolfgramm et al., 2015) entered the well from an unknown source; for security reasons, the well was closed immediately. Since the wellhead pressure increased to between 8 and $9 \mathrm{MPa}$ due to the inflowing gas, fresh water and heavier fluids were pumped into the well at rates of up to $20 \mathrm{~L} \mathrm{~s}^{-1}$ over $15 \mathrm{~h}$ (total volume of approx. $700 \mathrm{~m}^{3}$ ) to prevent further gas inflow (phase A.3 in Fig. $1 \mathrm{~b}$ and Fig. 1e). This injection successfully decreased the wellhead pressure. However, numerous seismic events were induced in the evening on 19 July, one triggering the yellow threshold of the installed traffic light system (TLS), meaning that injection should be stopped immediately (e.g., Diehl et al., 2017; Obermann et al., 2015). Nevertheless, injection was continued until the early morning of 20 July to keep the wellhead pressure at about $3 \mathrm{MPa}$; stopping the injection would probably have led to an increase in the wellhead pressure due to further gas inflow. Seismicity continued, and a $M_{\mathrm{L}} 2.1$ event was induced at 02:40 am on 20 July, followed by multiple smaller events. At 05:30 am, after more water, including heavy components, was injected, a $M_{\mathrm{L}} 3.5$ event was induced. Subsequently, the pressure normalized and the injection was stopped. The main shock was followed by almost 200 seismic events (relocated) until the end of July (Diehl et al., 2017) (Fig. 1b). After a preliminary analysis of the incidents, the geothermal project was temporally suspended. The main seismic sequence was followed by only minor seismicity between August and mid-September 2013 (phase B in Fig. 1a). Cleaning and fishing operations in the borehole from mid-September to mid-October likely led to a temporal increase in the seismicity rate due to some mud losses (phase $\mathrm{C}$ in Fig. 1a). During a production test conducted at the end of October, the seismicity ceased completely. Thereafter, the operators decided to permanently suspend the project because the permeability of the reservoir was much too low (flow rate $<6 \mathrm{~L} \mathrm{~s}^{-1}$ for a drawdown of approx. $1500 \mathrm{~m}$ in the borehole ( $\sim 15 \mathrm{MPa})$; Wolfgramm et al., 2015), and the gas content was found to be too high to maintain flow rates sufficient for economic feasibility of a hydrothermal power plant. EGS-type hydraulic stimulation 
(i.e., hydro-shearing) was not considered because the risk of further seismicity was judged to be too high (e.g., Moeck et al., 2015).

The spatial distribution and evolution over time of the induced seismicity is illustrated in Fig. 2. The seismic sequence extends along a relatively narrow band (width of several hundreds of meters) striking SSW-NNE and dipping approximately $70^{\circ}$ to WNW. During the injections in July 2013, the seismicity mainly propagated in the southwest direction from the borehole. Only from August to October 2013 did the seismicity start to propagate to the northeast but at much smaller propagation velocities (Diehl et al., 2017). The main focal mechanism in St. Gallen is strike-slip, which can be deduced from the two largest events of the sequence (Fig. 2). To measure the local stress field, Moeck et al. (2015) performed in situ stress estimations for borehole SG GT-1 and determined that the maximum $\left(S_{\mathrm{H}}\right)$ and minimum $\left(S_{\mathrm{h}}\right)$ principal stresses were horizontal trending $160 \pm 12$ and $70 \pm 12^{\circ}$, respectively. The vertical stress $\left(S_{\mathrm{V}}\right)$ was estimated to be intermediate with a magnitude of $98 \mathrm{MPa}$ at a depth of ca. $3.9 \mathrm{~km}$. Furthermore, the mean stress ratios of $S_{\mathrm{H}}=1.41 \cdot S_{\mathrm{v}}$ and $S_{\mathrm{h}}=0.61 \cdot S_{\mathrm{v}}$ were calculated at $4.1 \mathrm{~km}$ TVD. On a more regional scale, Kastrup et al. (2004) inverted focal mechanisms of naturally occurring earthquakes over the last 50 years to obtain the orientation of the three principal stresses in the Northern Alpine Foreland. They obtained a trend of about 160 to $170^{\circ}$ for the maximum horizontal stress - in good agreement with the in situ stress estimations. Assuming a straight planar fault, we calculate the best-fit strike orientation (least-squares regression) to be approximately $210^{\circ}$ (Fig. 2), coinciding with the focal mechanisms of the two largest induced events. Hence, in comparison to the local stress field, $S_{\mathrm{H}}$ intersects the fault with an angle of about $50^{\circ}$.

\section{Conceptual model}

First, we describe the conceptual model of the stimulation phase, the gas kick, and the subsequent well control injection in July 2013. Clearly, there is a temporal correlation between the seismicity and the fluid injected during the injection test, the acid stimulations, and the well control measures (Fig. 1). With regard to the spatial distribution, despite the estimated vertical and horizontal absolute location uncertainties of 0.15 and $0.1 \mathrm{~km}$, respectively (Diehl et al., 2017), most of the seismicity occurred in the pre-Mesozoic basement below a depth of $4.4 \mathrm{~km}$ (Fig. 3). Hence, considering the mean locations, the seismicity is separated from the well bottom (at a depth of ca. $4.2 \mathrm{~km}$ ) by a minimum distance of about $0.3 \mathrm{~km}$. The main shock $\left(M_{\mathrm{L}} 3.5\right)$ was located at a depth of about $4.6 \mathrm{~km}$, $0.2 \mathrm{~km}$ further southwest with respect to the top of the open well section. The spatial gap between the borehole and the seismicity suggests that the seismic events were triggered either remotely by poroelastic stress changes or by a hydraulic connection (e.g., a fracture zone or a damage zone of a fault;
Zbinden et al., 2020). Temperature and gamma-ray anomalies from borehole logs support a connection to the Lower Mesozoic sediments and possibly to the pre-Mesozoic basement (Wolfgramm et al., 2015). The temperature anomalies indicate the presence of major inflow zones intersecting with the borehole, the most prominent one at the upper part of the Malm (at a depth of $3.9 \mathrm{~km}$ ). In the gamma-ray log, thorium anomalies suggest a connection between the borehole and the Dogger layer (underlying the Malm reservoir) or deeper (Wolfgramm et al., 2015). From a geometrical analysis, Diehl et al. (2017) suggested that at least one fault mapped by the seismic survey (Heuberger et al., 2016) might act as a hydraulic connection. The presence of a hydraulic connection would suggest that the injected fluid moved from the borehole toward the fault, resulting in an increase in pore pressure and a decrease in effective normal stress, eventually destabilizing the fault and leading to seismicity (Zbinden et al., 2020). Models have shown that the seismicity can be significantly stronger for hydraulically connected faults than for unconnected faults (Chang and Segall, 2016). Since the seismic response in St. Gallen was unexpectedly intense, it would support the hypothesis of a hydraulic connection.

With respect to the gas kick, the gas may have originated from the PCT located below the Mesozoic sediments, which contains high concentrations of organic carbon (Heuberger et al., 2016; Wolfgramm et al., 2015). The gas might then have migrated upwards over geologic time, eventually reaching an impermeable seal preventing the gas from moving higher up. The stratigraphy in the St. Gallen region indicates that the Lower Mesozoic sediments (Keuper, Lias, and Dogger) could serve as a caprock to the gas reservoir. Additionally, the fault may have acted as a lateral seal to prevent the gas from reaching the hydraulic connection prior to the stimulations (Fig. 3). The gas kick first occurred $2 \mathrm{~d}$ after the acid stimulations and $5 \mathrm{~d}$ after the injection test, whereas no gas was observed during the drilling of the well (Naef, 2015). This is an indication that a hydraulic connection was indeed present, enabling the gas to enter the borehole from a greater depth. On the other hand, it implies that the hydraulic connection was only established after the injection test and the acid stimulations. Possibly, the stimulations enhanced the permeability of the hydraulic connection; the resulting seismicity as well as the acidification breached the fault seal, opening up a pathway for the gas to reach the well. This would imply that the gas took the same path as the injected fluid but in the opposite direction (Fig. 3).

In summary, we propose that the following processes could have led to the main seismicity sequence (1431 July 2013) in St. Gallen.

1. During the injection test and the acid stimulations, the fault was pressurized by a highly permeable hydraulic connection (whose permeability is enhanced by the pressurization and the acid treatment). 


\section{Cross-section normal to fault plane}
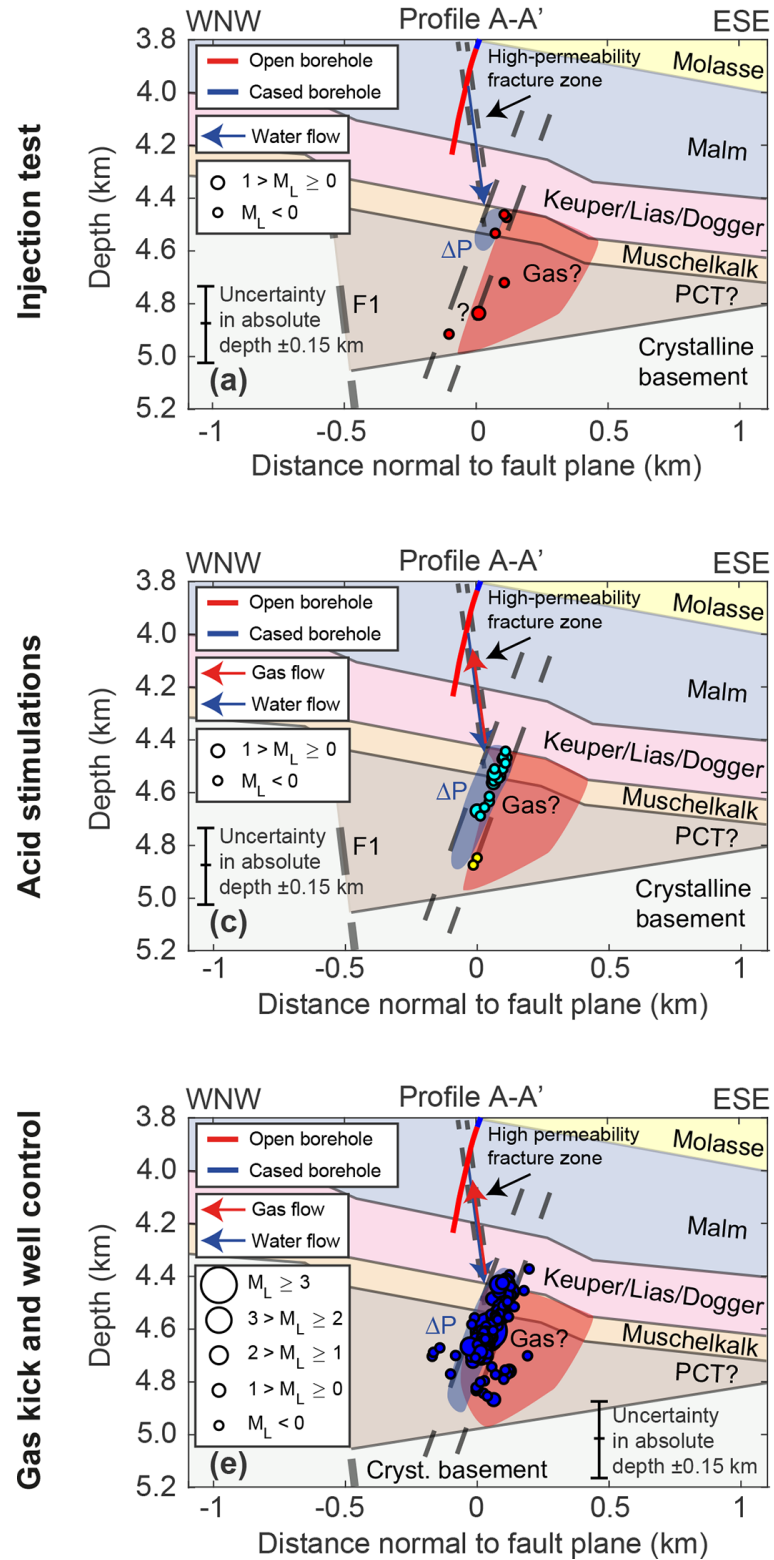

\section{Cross-section along fault plane}
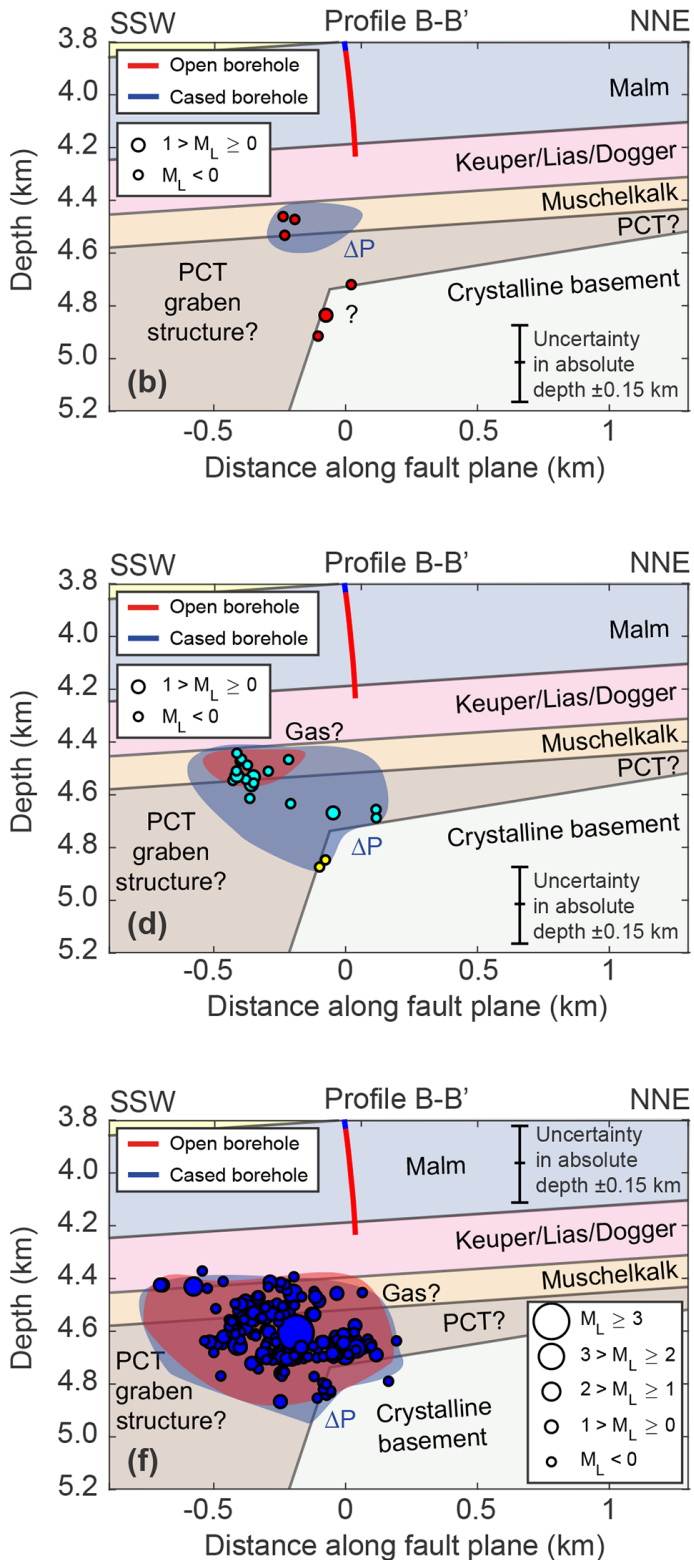

Figure 3. Conceptual model of the stimulation phase, the gas kick, and the well control measures in July 2013. (a, b) Seismicity of the injection test (14 July) on a profile (a) normal to (A-A' in Fig. 2) and (b) along (B- $\mathrm{B}^{\prime}$ in Fig. 2) the fault. The blue shaded area denotes the region affected by the direct pressurization, while the red shaded area depicts the possible location of the gas as described in the text (shown in all subfigures). The question mark next to the deeper events indicates that their location is probably an artifact that can be removed considering a local $v_{\mathrm{p}} / v_{\mathrm{s}}$ velocity anomaly (Diehl et al., 2017). (c, d) Seismicity due to the acid stimulations (17 July) on a profile (c) normal to and (d) along the fault. The yellow dots correspond to the seismicity induced during the first acid stimulation, while the cyan dots mark the events induced during the second acid stimulation. The red shaded area in (d) is the region affected by the proposed seal breach through which the gas may have migrated. (e, f) Seismicity during and after the well control measures (19-31 July) on a profile (e) normal to and (f) along the fault. The injected fluid and the gas that is intruding into the fault could have caused the seismic sequence including the $M_{\mathrm{L}} 3.5$ main shock. Depth is defined relative to the top of the borehole (i.e., the free surface). 
2. The pressure increase on the fault led to a decrease in the effective normal stress and caused minor seismicity (Fig. 3a-d).

3. Due to the acidification and shear slip associated with the fault reactivation, a pathway opened up for the gas to reach the borehole through the hydraulic connection and caused the gas kick (Fig. 3c and d).

4. The fluid injected into the well during the control measures and the gas destabilized a larger patch on the fault leading to the seismic sequence that included the $M_{\mathrm{L}} 3.5$ event (Fig. 3e and f).

5. The injection of water and drilling mud during the well control measures probably clogged the hydraulic connection and stopped the gas kick.

In our conceptual model, we show one distinct fracture zone that intersects with the borehole at the Upper Malm where a strong temperature anomaly was observed. However, the logs show that other permeable structures might exist at the depth of the Lower Malm. Moreover, for both the injection test and the first acid stimulation, Diehl et al. (2017) observed that the seismicity was initiated at a greater depth (between 4.8 and $5.0 \mathrm{~km}$ ) compared to later events. The first acid stimulation was performed in the lower section of the Malm and induced two microearthquakes at a depth of about $4.9 \mathrm{~km}$ (Fig. 3c and Fig. 3d). The second acid stimulation was performed in the Upper Malm section, inducing seismic events above a depth of $4.7 \mathrm{~km}$. For the injection test and the well control measures, where water and drilling mud was injected into the cased section and the well was pressurized equally, seismic event locations ranged from a depth of approximately 4.4 to $4.9 \mathrm{~km}$. Given these observations, the presence of a second permeable connection seems possible; the first structure connects the Upper Malm at the borehole with the reactivated fault at a depth of about $4.5 \mathrm{~km}$, while a second permeable structure may connect the Lower Malm with the fault at a depth of about $4.8 \mathrm{~km}$. The second hydraulic connection could then explain the fast seismic response to the stimulations in the lower part of the fault. However, despite these observations, Diehl et al. (2017) proposed that the vertical offset of this cluster is a location artifact, which can be removed considering the presence of a local $v_{\mathrm{p}} / v_{\mathrm{S}}$ velocity anomaly. For this reason, we choose to perform the numerical simulations with only one hydraulic connection.

Figure 4 shows the conceptual model for the poststimulation phase from August to December 2013. The seismicity of the main sequence (July 2013) was mainly distributed southwest of the injection well, whereas some minor events induced between August and mid-September 2013 were located northeast of it (Fig. 4a and b). In order to explain this observation, Diehl et al. (2017) argued that a seal, represented by a mapped fault intersecting with the reactivated fault in the area immediately beneath the borehole
(Heuberger et al., 2016), may have been breached by the 20 July main shock. Only after this event could the fluid flow to the northeast. Alternatively, it can be argued that the permeability of the reactivated fault was lower to the northeast, since the PCT probably tapers off in this direction (Fig. 4b and Fig. 4d, see also Fig. 11 in Heuberger et al., 2016), and hence the fault may contain lower-permeability components from the suggested crystalline horst. In this case, the pressure front would then propagate slower to the northeast, consistent with the seismic observations. From mid-September to the end of October 2013, the seismicity increased again in the area below the borehole, although not drastically (Fig. 4c and d). At the same time, mud loss was observed in borehole SG GT-1 due to some fishing and cleaning operations. This indicates that the hydraulic connection, possibly clogged by the well control injection, may have been reopened, and the mud was able to reach the fault plane. Subsequently, the seismicity continued to propagate further to the northeast, while no seismic activity was observed southwest of the borehole. This may be associated with renewed gas movement due to the pressure changes caused by the mud. It is possible that the mud clogged potential pathways to the southwest, and hence the gas could only propagate to the northeast, inducing the seismicity in this region. Alternatively, the mud itself and some gas may have propagated to both the southwest and northeast but only induced seismic events in the northeast because the fault might possibly terminate in the southwest. We do not have data that supports any of these hypotheses, and, therefore, we cannot assess whether the seismicity in the post-injection period was induced by the gas, the mud, or a mixture of both. The seismicity in St. Gallen ceased during a production test at the end of October 2013. It was observed that the entire seismic sequence was constrained below a depth of about $4.4 \mathrm{~km}$ (Figs. 3 and 4), which coincides with the top boundary of the Muschelkalk. The reason for this may be (i) a stiffness contrast of the softer Keuper, Lias, and Dogger layers with respect to the stiffer Muschelkalk and Malm layers, which absorb most of the tectonic stress, leading to a lower differential stress in the softer layers and therefore to a less critically stressed fault in this region (Hergert et al., 2015), or (ii) a lower permeability of the reactivated fault due to the surrounding low-permeability layers (Keuper, Lias, and Dogger) and thus a smaller pressurization above the Muschelkalk - as assumed in our conceptual model.

\section{Model setup and calibration}

The numerical simulations are performed using TOUGH2seed (Rinaldi and Nespoli, 2017). The seismic module of TOUGH2-seed is switched off during the simulation of the injection test and the gas kick to simplify the calibration of the model; however, we use the full model during the simulation of the main seismic sequence. 


\section{Cross-section normal to fault plane}
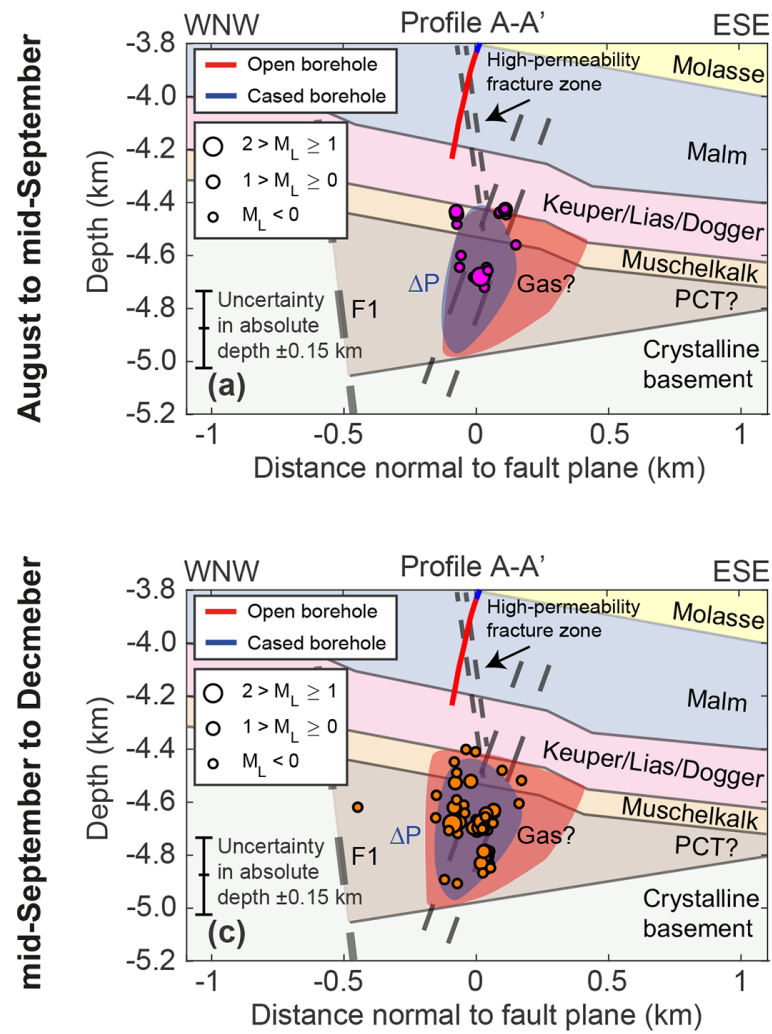

\section{Cross-section along fault plane}
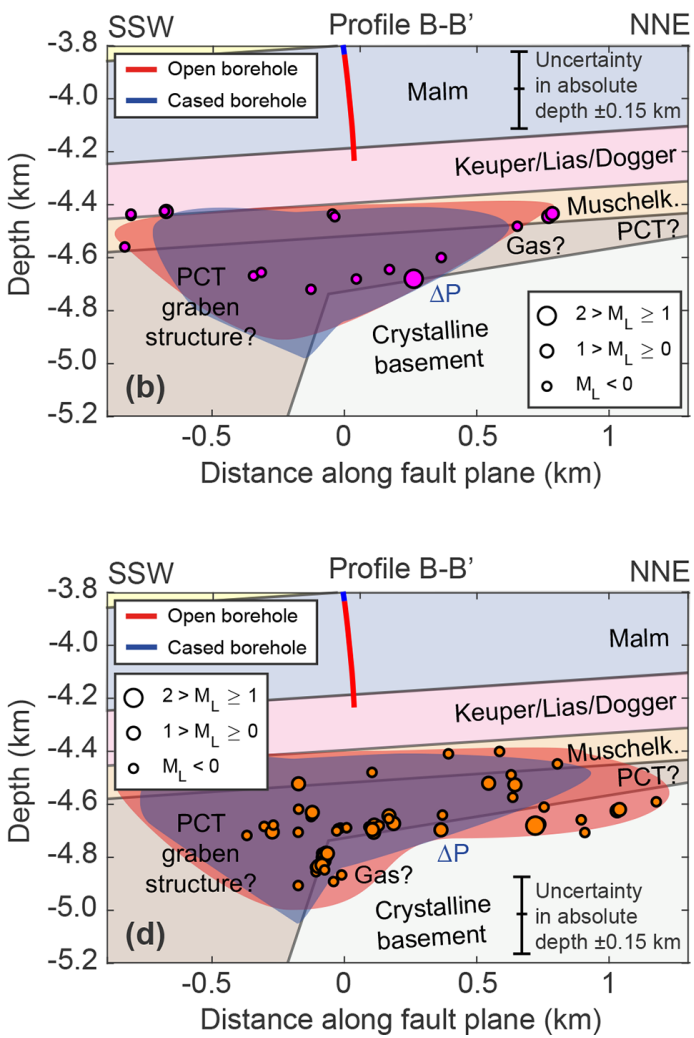

Figure 4. Conceptual model of the post-stimulation phase from August to December 2013. (a, b) Seismicity for the period 1 August to 15 September on a profile (a) normal to (A-A' in Fig. 2) and (b) along (B-B' in Fig. 2) the fault. The blue shaded area denotes the region affected by the direct pressurization, while the red shaded area depicts the possible location of the gas (shown in all subfigures). The seismicity in July is mainly located on the southwestern side of the borehole, whereas the seismic events after 1 August start to propagate to the northeast. (c, d) Seismicity of the period from 16 September to the end of 2013 on a profile (c) normal to and (d) along the fault. Borehole operations associated with some mud loss may be responsible for the increase in seismicity in September and October. The seismicity propagates further to the northeast but ceases during a production test at the end of October. Depth is defined relative to the top of the borehole (i.e., the free surface).

\subsection{TOUGH2-seed}

TOUGH2-seed couples TOUGH2 with a stochasticgeomechanical model (Catalli et al., 2016; Gischig and Wiemer, 2013; Gischig et al., 2014; Goertz-Allmann and Wiemer, 2013). TOUGH2 is a multiphase, multicomponent, and heat transport numerical simulator based on a first-order implicit finite difference scheme in time and an integral finite difference method in space (Pruess et al., 2012). After the computation of the pressure field in TOUGH2, the solution is passed on to the seed model for each time step. TOUGH2-seed incorporates two different modules: (i) the hydraulic module that is similar to TOUGH2 but accounts for pressure-dependent permeability and (ii) a seismic module that simulates induced seismicity and can be switched off if no seeds are distributed in the model. Seeds are uniformly randomly distributed potential failure points with prescribed stress and failure conditions. The hydraulic and seismic modules can be fully coupled if the permeability is chosen to be dependent on the seismicity (Gischig et al., 2014; Rinaldi and Nespoli, 2017). TOUGH2-seed has been successfully applied to the EGS project in Basel, where most of the characteristic behavior of the induced seismicity could be reproduced (Rinaldi and Nespoli, 2017). The main advantage of using a stochastic model is that uncertainties can be assigned to different model parameters (e.g., stress magnitude, fault orientation, friction) depending on how well they are constrained by field data. Synthetic earthquake catalogs can be obtained after each simulation, allowing a comparison to observed earthquake data.

In this study, the pressure $P$ strictly refers to the average pore pressure (summation over fluid phases) exerted by the gas and liquid phases (e.g., Kim et al., 2013), written as

$P=S_{\mathrm{g}} \cdot P_{\mathrm{g}}+\left(1-S_{\mathrm{g}}\right) \cdot P_{\mathrm{w}}$,

where $S_{\mathrm{g}}$ is the gas saturation, $P_{\mathrm{g}}$ the gas pressure, and $P_{\mathrm{w}}$ the water pressure. Here we ignore the interfacial energy 
caused by the two-phase system (Kim et al., 2013, and references therein). For the hydraulic module, we account for pressure-dependent permeability following Rinaldi and $\mathrm{Ne}$ spoli (2017):

$\kappa_{\mathrm{hm}}=\kappa \cdot \exp \left[C_{1}\left(\frac{\phi_{\mathrm{hm}}}{\phi_{0}}-1\right)\right]$

$\phi_{\mathrm{hm}}=\left(\phi-\phi_{\mathrm{r}}\right) \cdot \exp (\alpha \Delta P)+\phi_{\mathrm{r}}$,

where $C_{1}$ and $\alpha\left(\mathrm{Pa}^{-1}\right)$ are scaling parameters. The updated permeability $\kappa_{\mathrm{hm}}$ is a function of the initial permeability $\kappa$ and the ratio of the actual porosity $\phi_{\mathrm{hm}}$ and the initial porosity $\phi . \phi_{\mathrm{hm}}$ is exponentially dependent on the pore pressure change $\Delta P$ and linearly dependent on the difference between $\phi$ and the residual porosity $\phi_{\mathrm{r}}$. Note that the permeability and porosity changes in Eqs. (2) and (3) are reversible (i.e., purely elastic). For the seismic module, TOUGH2-seed takes into account the full 3D stress state formulation as well as the static Coulomb stress transfer (Catalli et al., 2016; Rinaldi and Nespoli, 2017). TOUGH2 solves for the pore pressure in each model element and transfers it to the seed model, where the new stress state of the seeds is computed according to the analysis of effective stress (Terzaghi, 1923):

$\sigma_{i j}^{\prime}=\sigma_{i j}-P$,

where $\sigma_{i j}^{\prime}$ is the effective stress tensor, and $\sigma_{i j}$ is the total stress tensor. The current version of TOUGH2-seed does not account for poroelasticity; i.e., the total stresses do not change due to pressure and vice versa. The initial stress state on the seeds follows a normal distribution around a mean regional stress field in order to account for stress heterogeneity that can be present in reality. The seeds are distributed on a fault, and their orientation is normally distributed around the strike $(\gamma)$ and $\operatorname{dip}(\theta)$ of the fault. From the orientation and the given effective stress tensor of the seeds, the effective normal stress $\sigma_{\mathrm{n}}^{\prime}$ and the shear stress $\tau$ can be computed (e.g., Zoback, 2010). A seed is triggered if a Mohr-Coulomb failure criterion is reached, i.e., when the shear stress exceeds the shear strength $\tau_{\mathrm{s}}$ (critical shear stress):

$\tau_{\mathrm{s}}=c+\mu_{\mathrm{s}} \cdot \sigma_{\mathrm{n}}^{\prime}$,

where $c$ is the cohesion and $\mu_{\mathrm{s}}$ the static friction coefficient, which follows a normal distribution (i.e., the strength of the seeds varies). Moreover, following Gischig and Wiemer (2013), we define a criticality threshold $\mu_{\mathrm{c}}$, so that the stress states of the seeds at the beginning of the simulation have a certain gap to the failure criterion. A moment magnitude is assigned to each triggered seed, randomly chosen from a Gutenberg-Richter (GR) distribution with a fixed $b$ value of 1.2 and a magnitude of completeness $\left(M_{\mathrm{c}}\right)$ of 0.8 obtained from the St. Gallen catalog and recalculated for $M_{\mathrm{w}}$ using a corrected maximum likelihood method (e.g., Marzocchi and Sandri, 2003, and references therein). A shear stress drop
$\Delta \tau$ is calculated for each reactivation given by Gischig et al. (2014)

$\Delta \tau=\Delta \tau_{\text {coeff }} \cdot\left(\frac{\tau-c}{\mu_{\mathrm{S}}}\right)$,

where $\Delta \tau_{\text {coeff }}$ is a coefficient determining how much shear stress is released. A new stress state is then computed on the reactivated seed and on all neighboring seeds that are affected by the static stress transfer. After the evaluation of the triggered seeds, the permeability is updated, and TOUGH2 solves for the pressure distribution of a new time step before the coupling is repeated.

\subsection{Numerical model setup}

The 3D hydrogeological model consists of a fracture zone connecting the upper part of the open section of the borehole (at a depth of approx. $3.9 \mathrm{~km}$ ) with a fault plane intersecting a caprock layer (Fig. 5). The fracture zone dips $77^{\circ}$ and is therefore a conjugate plane of the reactivated fault, which itself dips $70^{\circ}$ toward the WNW. The fracture zone extends over a length of about $920 \mathrm{~m}$ along the dip from a depth of 3.6 to $4.5 \mathrm{~km}$, where it is bound by the fault. The top corresponds to the base of the Molasse sediments (not modeled), where the fracture zone is presumed to taper off. Furthermore, the fracture zone is assumed to have an along-strike length of $250 \mathrm{~m}$. The fracture zone is modeled as a highpermeability, low-porosity, and high-compressibility equivalent porous medium with a thickness of $20 \mathrm{~m}$. The permeability in the fracture zone is pressure-dependent to account for fracture opening during injection (initial permeability, pore compressibility, and $\alpha$ in Eq. 3 are calibration parameters). We assume a very small initial porosity of $3 \times 10^{-5}$, corresponding to a total void space of $600 \mu \mathrm{m}$ within the $20 \mathrm{~m}$ thick equivalent porous medium domain (e.g., $10 \mathrm{frac}-$ tures with an aperture of $60 \mu \mathrm{m}$ each). The fault zone consists of a two-sided, $2 \times 20 \mathrm{~m}$ wide permeable damage zone $\left(\kappa=10^{-14} \mathrm{~m}^{2}\right)$ and a $5 \mathrm{~m}$ wide, impermeable fault core $(\kappa=$ $10^{-22} \mathrm{~m}^{2}$ ), and it extends over the entire width and length of the model ( $2 \mathrm{~km}$ in the $y$ and ca. $1.9 \mathrm{~km}$ in the $z$ direction). The fault intersects a slightly inclined, very low permeability caprock $\left(\kappa=10^{-22} \mathrm{~m}^{2}\right)$ corresponding to the Lower Mesozoic sediments (Keuper, Lias, and Dogger). A host rock layer representing the Malm reservoir surrounds the open section of the well. For simplicity, we assume that the domain below the caprock has the same properties as the host rock (Fig. 5a). The well is approximated as a high-porosity and high-permeability porous medium, under the assumption of negligible dynamic pressures within the wellbore (well permeability is a calibration parameter; Rinaldi et al., 2017). For the multiphase flow modeling, we use the relative permeability curves of Corey (1954) and capillary pressure functions of van Genuchten (1980). A summary of the hydraulic parameters is given in Table 1. 

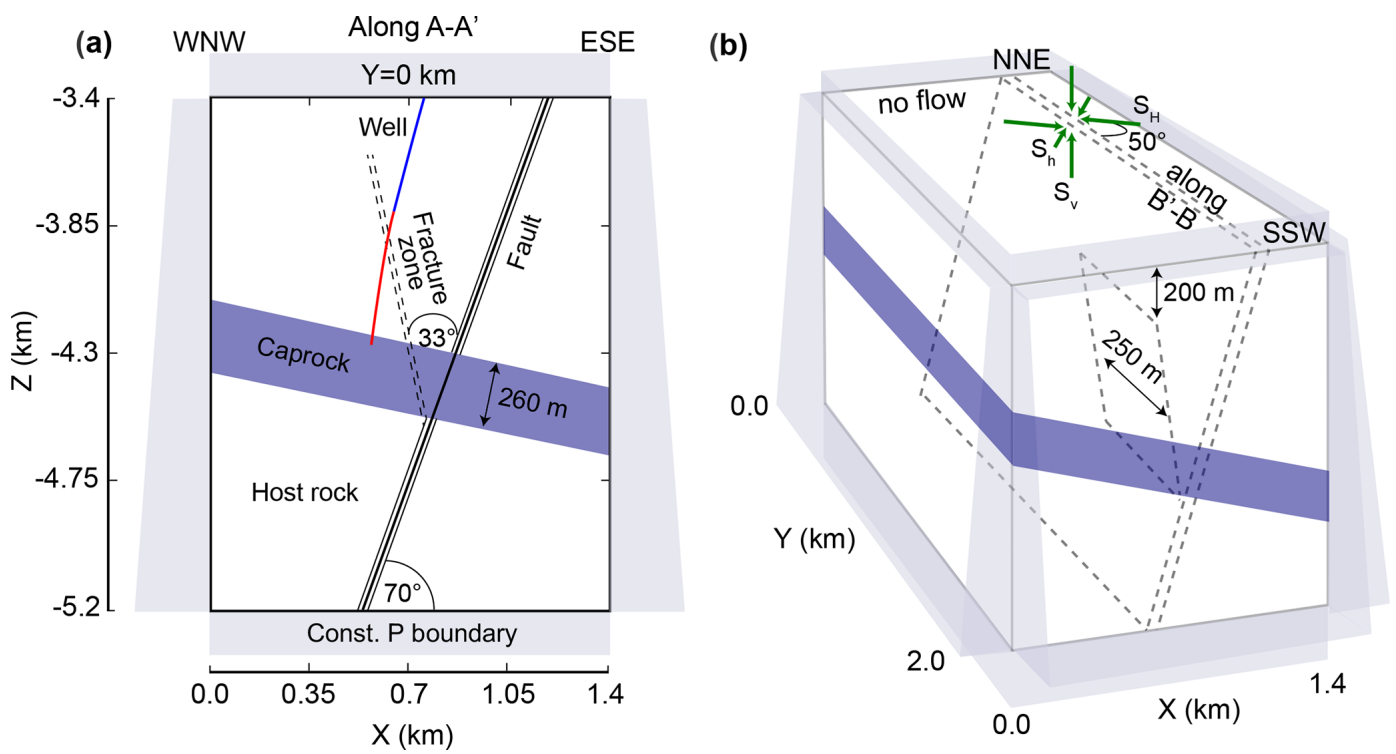

Figure 5. Schematic of the 3D numerical model: (a) slice at $y=0 \mathrm{~km}$ (along profile $\mathrm{A}-\mathrm{A}^{\prime}$ in Fig. 2). The well is indicated by the blue (cased section) and red lines (open section). (b) Entire 3D model along the strike of the fracture zone and fault (along profile B-B' in Fig. 2). The dark green arrows indicate the orientation of the mean stress field used for the TOUGH2-seed simulations.

Table 1. Predefined and calibrated hydraulic parameters of the numerical model.

\begin{tabular}{lrrrrrr}
\hline & Host rock & Fracture zone & Damage zone & Fault core & Caprock & Well open/cased \\
\hline Initial porosity $\phi(-)$ & $0.05^{\mathrm{a}}$ & $3 \times 10^{-5}$ & 0.10 & 0.01 & 0.01 & $0.90 / 0.99$ \\
Residual porosity $\phi_{\mathrm{r}}(-)$ & 0.05 & 0.00 & 0.10 & 0.01 & 0.01 & $0.90 / 0.99$ \\
Initial permeability $\kappa\left(\mathrm{m}^{2}\right)$ & $10^{-18^{\mathrm{b}}}$ & $1.3 \times 10^{-14^{\mathrm{c}}}$ & $10^{-14}$ & $10^{-22}$ & $10^{-22}$ & $1.5 \times 10^{-8^{\mathrm{c}}} / 10^{-5}$ \\
$C_{1}(-)$ & - & $57.3^{c}$ & - & - & - & - \\
$\alpha\left(\mathrm{Pa}^{-1}\right)$ & - & $10^{-8}$ & - & - & - \\
Pore compressibility $c_{\phi}\left(\mathrm{Pa}^{-1}\right)$ & $5 \times 10^{-10}$ & $3.7 \times 10^{-8^{\mathrm{c}}}$ & $5 \times 10^{-10}$ & $5 \times 10^{-9}$ & $5 \times 10^{-9}$ & $5 \times 10^{-11}$ \\
Residual gas saturation $S_{\mathrm{gr}}(-)$ & 0.05 & 0.05 & 0.05 & 0.05 & 0.05 & 0.05 \\
Residual liquid saturation $S_{\mathrm{lr}}(-)$ & 0.3 & 0.05 & 0.1 & 0.3 & 0.3 & 0.05 \\
van Genuchten $(1980), P_{0}(\mathrm{MPa})$ & 2.0 & $2.4 \times 10^{-3}$ & 0.02 & 19.9 & 19.9 & 0.9 \\
van Genuchten $(1980), m(-)$ & 0.457 & 0.457 & 0.457 & 0.457 & 0.457 & 0.457 \\
\hline
\end{tabular}

a Moeck et al. (2015) and Wolfgramm et al. (2015). ${ }^{\mathrm{b}}$ Wolfgramm et al. (2015). ${ }^{\mathrm{c}}$ calibrated.

In accordance with the in situ conditions measured in borehole SG GT-1 in St. Gallen (Wolfgramm et al., 2015), we initialize the pressure at approx. $37 \mathrm{MPa}$ and the temperature at $143{ }^{\circ} \mathrm{C}$ at the top of the open well section. The temperature linearly increases with depth by $35.5^{\circ} \mathrm{C} \mathrm{km}^{-1}$ and is held constant during the injection. Although injection of low-temperature fluid can cool the rock and influence both the stress and pressure conditions (e.g., Ghassemi and Tao, 2016; Hopp et al., 2019; Rinaldi et al., 2015), we do not expect a significant cooling effect over the relatively shortterm and small-volume injection that occurred in St. Gallen. We choose the boundaries to be open for fluid flow everywhere except at the boundary $y=0 \mathrm{~km}$ (symmetry boundary), where we apply no flow conditions (Fig. 5b). In order to model the multiphase fluid system, we employ an equa- tion of state with water and air as liquid and gas phase, respectively. Methane and nitrogen (air contains approx. $78 \%$ nitrogen by volume) are both in a supercritical state at reservoir conditions (e.g., Nasrifar and Bolland, 2006); i.e., their dynamic viscosity is similar to a gas, and their density is between a liquid and a gas. We therefore consider the use of air instead of methane to be an appropriate approximation for the purposes of this study. We create an initial steadystate condition of a gas plume below the caprock on the right side of the fault by simulating gas inflow with a pressure of $70 \mathrm{MPa}$ at the lower boundary into the right damage zone for $1 \mathrm{Myr}(0.1 \mathrm{~km}$ long line source along the $y$ axis $)$. To prevent gas leakage, we assign a high capillary entry pressure to the fault core and the caprock. Figure 6 shows the initial pressure distribution and gas saturation at three different vertical 
cross sections. The pressure increase is approximately linear with depth (approx. 9.1 $\mathrm{MPa} \mathrm{km}^{-1}$ ) above the caprock, while it is highly disturbed below the caprock by the overpressurized gas plume (i.e., pressurized with respect to an undisturbed state without gas). At the fracture zone/fault intersection at $y=0 \mathrm{~km}$ (at a depth of $4.5 \mathrm{~km}$ ), the pressure on the right side of the fault exceeds the pressure on the left by about $7 \mathrm{MPa}$. This pressure difference becomes less pronounced toward the boundary at $y=2 \mathrm{~km}$ (Fig. 6a to c). The plume is completely gas saturated in the right damage zone and in the adjacent host rock at $y=0 \mathrm{~km}$, while the size of the plume decreases along the strike of the fault (Fig. 6d to f). The domain below the caprock on the left side of the fault has an initial gas saturation of $5 \%$.

The stress input for the seed model is based on the findings of Moeck et al. (2015). The maximum principal stress $S_{1}$ is horizontal and has a mean trend of $160^{\circ}$; the intermediate principal stress $S_{2}$ is equal to the vertical stress $S_{\mathrm{v}}$, and the minimum principal stress $S_{3}$ is horizontal with a trend of $70^{\circ}$. The seeds are randomly distributed on the lower part of the fault $(z \leq-4.5$ and $y \leq 1.0 \mathrm{~km})$ and in the immediate surroundings, not more than $90 \mathrm{~m}$ normal distance to the fault core. Due to uncertainties in the exact orientation of the principal stresses with respect to the reactivated fault plane, we assign a standard deviation of $12^{\circ}$ on both the dip (mean of $70^{\circ}$ ) and the strike of the seeds (the latter is equivalent to a $12^{\circ}$ uncertainty in the horizontal stress orientations). The mean strike of the seeds is $210^{\circ}$, thus exhibiting an average angle of $50^{\circ}$ with respect to $S_{1}$. We assume the seeds to have a coefficient of friction of $0.6 \pm 0.05$ and a cohesion of $1 \mathrm{MPa}$. For the vertical stress magnitude, starting from $S_{\mathrm{v}}=85.3 \mathrm{MPa}$ at a depth of $3.4 \mathrm{~km}$, we use a stress gradient of $26.0 \mathrm{MPa} \mathrm{km}^{-1}$ according to density estimations from borehole samples (rock density $\rho=2650$ $\mathrm{kg} \mathrm{m}^{-3}$; Alber and Backers, 2015, and references therein). We set $S_{\mathrm{H}}=(1.41 \pm 0.39) \cdot S_{\mathrm{V}}$ and $S_{\mathrm{h}}=(0.61 \pm 0.08) \cdot S_{\mathrm{V}}$, while the standard deviation of $S_{\mathrm{V}}$ is set to 0.03 . Note that all parameters in the seed model, except for the coefficient of friction and the state of stress that follow a normal distribution, are assumed to be constant. A list of the seed model parameters is given in Table 2.

\subsection{Model calibration}

We calibrate some of the hydraulic parameters against the bottom hole and wellhead pressure of the injection test, while the remaining parameters are taken from data or are reasonably assumed from the literature. We use iTOUGH2-PEST (Finsterle and Zhang, 2011) for the calibration according to the approach of a recent study using a coupled hydromechanical model (Rinaldi et al., 2017). The injection test is best suited for model calibration, since the area surrounding the borehole was not affected by previous stimulation. In addition, bottom hole pressures, probably more representative of the reservoir properties, are only available for the injec- tion test. The pressure data from the acid stimulations are less useful for calibration, since the acidification may have changed the permeability of the carbonate rocks by dissolution, which is not considered in this study. Similarly, pressure data from the gas kick and well control injection are strongly affected by multiphase fluid interactions, which prevents a straightforward calibration.

The misfit between the observed and simulated bottom hole and wellhead pressure data is minimized using a Levenberg-Marquardt algorithm. We put 4 times more weight on the bottom hole data, since they are directly coupled to the hydraulic properties of the reservoir. We account for the wellhead pressure to obtain realistic well properties, because the injection occurs in the upper part of the cased borehole. The parameters we invert for are (i) the initial fracture zone permeability, (ii) the parameter $C_{1}$ in the permeability-pressure relationship for the fracture zone (Eq. 2), (iii) the fracture zone compressibility, and (iv) the permeability of the open section of the well.

In order to get a reasonably good fit for the pressure curve, we need to capture the typical fracture opening behavior at $\Delta P \simeq 6 \mathrm{MPa}$ (sharp kink shortly after the start of injection) as well as the post-shut-in behavior that is observed in the data (Fig. 7a). These two observations can be reproduced with an initial fracture zone permeability of $1.3 \times 10^{-14} \mathrm{~m}^{2}$ that increases to a maximum permeability of $5.4 \times 10^{-13} \mathrm{~m}^{2}$ at $\Delta P=9.4 \mathrm{MPa}\left(C_{1}=57.3, \alpha=10^{-8}\right)$ after $2 \mathrm{~h}$ of injection. Using the cubic law (Witherspoon et al., 1980), these permeabilities correspond to 10 fractures, each with a hydraulic aperture of about 70 (initial) and $235 \mu \mathrm{m}$ (fully pressurized). Both the absolute fracture permeability and its changes are within expected ranges derived from in situ data in fractured rock (e.g., Rutqvist, 2015). For the remaining two inversion parameters, we obtain a fracture zone compressibility of $3.7 \times 10^{-8} \mathrm{~Pa}^{-1}$ and a permeability of the open well section of $1.5 \times 10^{-8} \mathrm{~m}^{2}$.

\section{Numerical results and discussion}

\subsection{Injection test}

We use the simulation run of the model calibration to quantify the timing and the magnitude of the pressure changes within the fracture zone and on the fault during the injection test. Figure $7 \mathrm{~b}$ shows the pressure change over time at different points in the fracture zone (P1 and P2) and in the fault (P3), whose locations are specified in Fig. 7c. For all three points, a delay and an attenuation of the pressure response with respect to the well (Fig. 7a) can be observed. While the pressure at the center of the fracture zone $(\mathrm{P} 1)$ increases by a maximum of about $5 \mathrm{MPa}$, the change is only about $1.6 \mathrm{MPa}$ further down in the fracture zone (P2) and $0.8 \mathrm{MPa}$ on the fault (P3). Despite the delayed response on the fault, an increase of about $0.2 \mathrm{MPa}$ is observed after $1.3 \mathrm{~h}$ when the seis- 

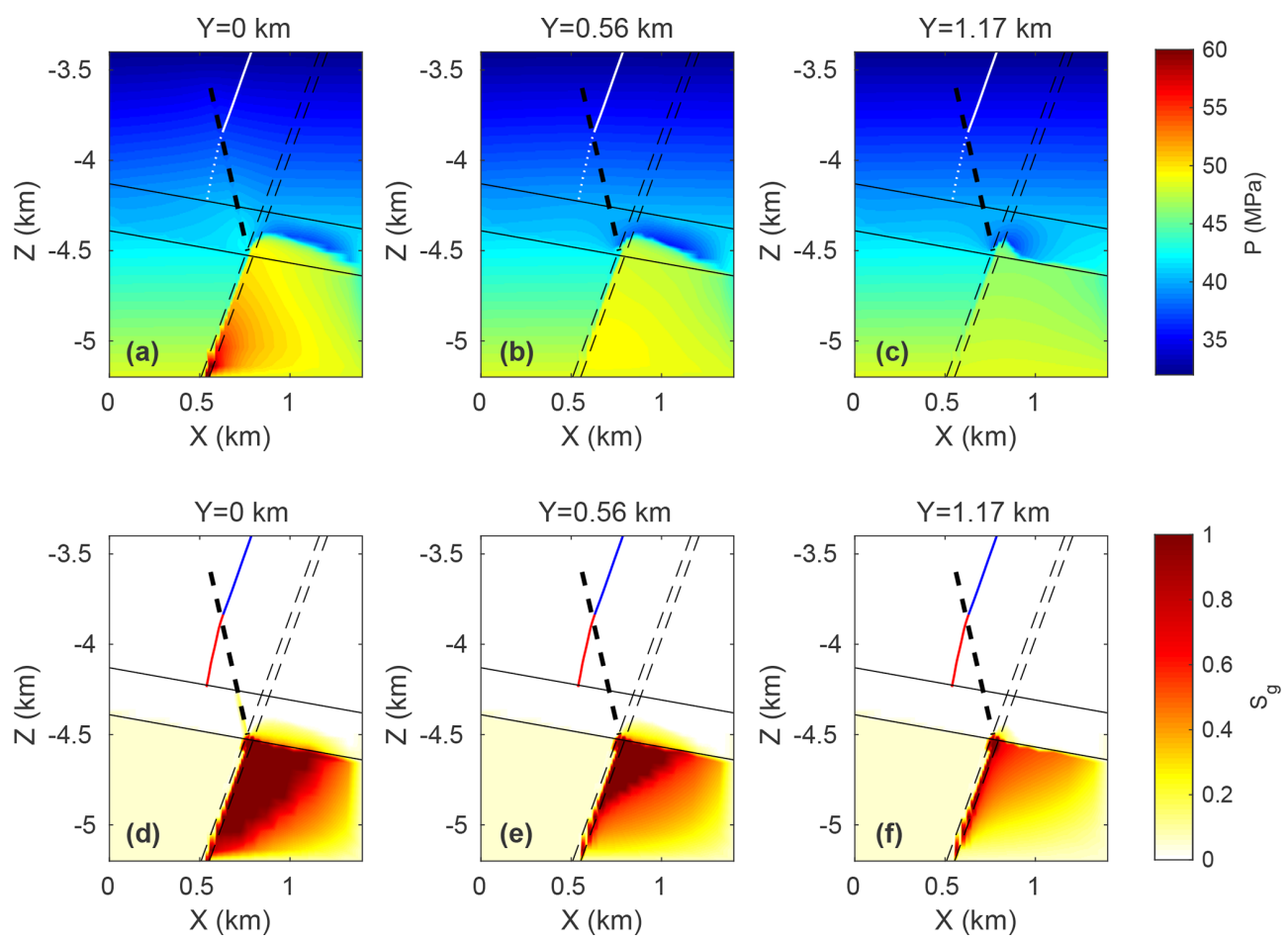

Figure 6. Initial conditions of the model: (a-c) Pressure at (a) $y=0$, (b) $y=0.56$, and (c) $y=1.17 \mathrm{~km}$ along profile A-A' in Fig. 2 (normal to the strike of the fault). The well is denoted by the dotted (open section) and solid (cased section) white line. (d-f) Gas saturation at (d) $y=0$, (e) $y=0.56$, and (f) $y=1.17 \mathrm{~km}$ along the profile $\mathrm{A}-\mathrm{A}^{\prime}$ in Fig. 2. The well is denoted by the red (open section) and blue (cased section) lines. The fault is illustrated by the thin dashed black lines, the fracture zone by the thick dashed black line, and the caprock by the solid black lines.

Table 2. Parameters used for the seed model.

\begin{tabular}{ll}
\hline Shear modulus $G$ & $4 \mathrm{GPa}$ (used for static stress transfer calculation) \\
Poisson's ratio $v$ & 0.25 (used for static stress transfer calculation) \\
Rock density $\rho$ & $2650 \mathrm{~kg} \mathrm{~m}^{-3}$ (Alber and Backers, 2015, and references therein) \\
Cohesion $c$ & $1 \mathrm{MPa}$ \\
Static friction coefficient $\mu_{\mathrm{s}}$ & $0.6 \pm 0.05$ \\
Criticality threshold $\mu_{\mathrm{c}}$ & 0.01 \\
Stress drop coefficient $\Delta \tau_{\text {coeff }}$ & 0.05 \\
$b$ value & 1.2 (recalculated from Diehl et al., 2017 for $\left.M_{\mathrm{W}}\right)$ \\
Magnitude of completeness $M_{\mathrm{c}}$ & $0.8\left(\right.$ recalculated from Diehl et al., 2017 for $\left.M_{\mathrm{W}}\right)$ \\
Maximum horizontal stress $S_{\mathrm{H}}(z=-3.8 \mathrm{~km})$ & $134.9 \pm 37.8 \mathrm{MPa}$ trend $160 \pm 12^{\circ}(\mathrm{Moeck}$ et al., 2015$)$ \\
Vertical stress $S_{\mathrm{v}}(z=-3.8 \mathrm{~km})$ & $95.7 \pm 2.9 \mathrm{MPa}(\mathrm{Moeck}$ et al., 2015) \\
Minimum horizontal stress $S_{\mathrm{h}}(z=-3.8 \mathrm{~km})$ & $58.4 \pm 7.6 \mathrm{MPa}$ trend $70 \pm 12^{\circ}(\mathrm{Moeck}$ et al., 2015) \\
Fault strike $\gamma$ & $210^{\circ}(\mathrm{Diehl}$ et al., 2017) \\
Fault dip $\theta$ & $70^{\circ}(\mathrm{Diehl}$ et al., 2017) \\
\hline
\end{tabular}

micity in St. Gallen was initiated (Diehl et al., 2017). Figure $7 \mathrm{c}$ illustrates the pressure change and the relocated seismic events of the injection test on a cross section normal to the fault $(y=0 \mathrm{~km})$ after $2 \mathrm{~h}$ of simulation time. The uppermost three events are close to the fracture zone/fault intersection and can be explained by the direct effect of the pressure caused by the injection, whereas the deeper events are outside the pressurized region. This can also be seen in Fig. 7d and e, where the pressure change and the induced events are shown along the fault after 2 and ca. $4 \mathrm{~h}$, respectively. The three deeper events could be explained by a second fracture zone connecting the well with the reactivated fault at greater depth. However, as mentioned in Sect. 3, the location of the deeper events is probably an artifact (Diehl et al., 2017), which would allow an explanation of all the induced events with only one fracture zone.

Recently, Zbinden et al. (2020) used a hydromechanically coupled model to compare different scenarios with and with- 

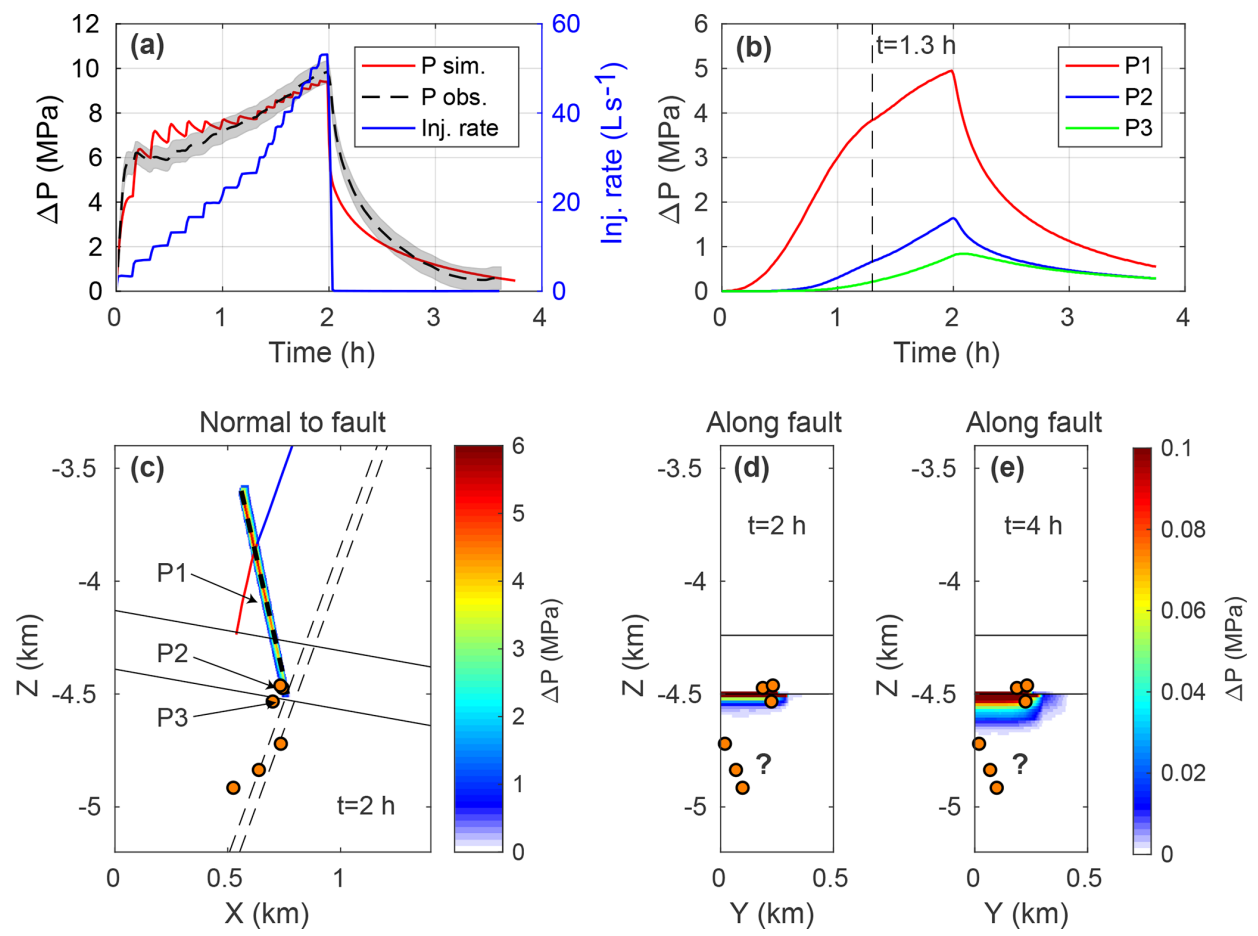

Figure 7. Simulated pressure change during the injection test. (a) Comparison of the measured and simulated pressure at the open section of the well after the model calibration with iTOUGH2-PEST. The shaded area denotes an error bound of $0.5 \mathrm{MPa}$ of the measured pressure. (b) Pressure change over time at different points marked in (c): P1 in the fracture zone at a depth of ca. $4.2 \mathrm{~km}, \mathrm{P} 2$ at the fracture zone/fault intersection in the fracture zone, and $\mathrm{P} 3$ at the fracture zone/fault intersection in the fault. The dashed black line marks the onset of seismicity at about $1.3 \mathrm{~h}$. (c) Pressure change after $2 \mathrm{~h}$ at $y=0 \mathrm{~km}$ (along profile $\mathrm{A}-\mathrm{A}^{\prime}$ in Fig. 2). The well is denoted by the red (open section) and blue (cased section) lines. The orange dots are the projections of the relocated events recorded during the injection test. (d-e) Pressure change after (d) 2 and (e) ca. $4 \mathrm{~h}$ along the fault (left damage zone, along profile $\mathrm{B}^{\prime}-\mathrm{B}$ in Fig. 2). The orange dots are the projections of the relocated events recorded during the injection test. The location of the three deeper events is probably an artifact that can be corrected taking into account a local $v_{\mathrm{p}} / v_{\mathrm{s}}$ velocity anomaly (Diehl et al., 2017).

out hydraulic connection. In the case of no connection, stress changes on the fault were purely governed by poroelasticity. Although the results showed that the induced events of the injection test all lay in regions of positive Coulomb stress change (i.e., in regions promoting failure), the magnitude of the stress changes was on the order of $10^{-3} \mathrm{MPa}$ or lower, which is about 3 orders of magnitude smaller than in the case of a hydraulic connection (Fig. 7). In order to explain the induced seismicity, Zbinden et al. (2020) concluded that the reactivated fault in St. Gallen was most probably hydraulically connected to the well. This interpretation was in contrast to another study in which the St. Gallen deep geothermal project was classified as a site where poroelastic effects, rather than the direct influence of the injection and the associated increase in pore pressure, predominate at a greater distance from the well (Goebel and Brodsky, 2018). However, in view of our conceptual model with its supporting observations for a hydraulic connection and the results from previous simulations (Zbinden et al., 2020), a scenario without hydraulic connection is much less plausible than the fracture zone scenario examined here.
The results show that the small injection volume of $175 \mathrm{~m}^{3}$ during the injection test is sufficient to cause a significant increase in pore pressure on the distant fault and can thus promote fault reactivation. Although not modeled here, the same mechanism may have occurred for the acid stimulations, where more fluid was injected (roughly $290 \mathrm{~m}^{3}$; Alber and Backers, 2015, and references therein), and hence more seismicity was induced. Zbinden et al. (2020) found that several fracture zone parameters affect the pressure response at the well and on the fault. For calibrated models, however, the response in terms of pressure and stress changes was comparable, thus leading to similar conclusions. The strong pressure increase during the injection test raises the question why the connecting fracture zone was not reactivated itself, since in our model, it underwent pressure changes of several megapascals . On the one hand, a higher shear strength (i.e., higher friction or cohesion) of the fracture zone may be sufficient to prevent reactivation. Moreover, stress modeling has shown that the differential stress acting on the weaker Keuper, Lias, and Dogger formation, where the fracture zone mainly cuts through, may be lower than in other formations (Hergert 
et al., 2015). Hence, the fracture zone may be less critically stressed than the reactivated fault. On the other hand, we cannot exclude that the fracture zone was indeed reactivated but underwent only aseismic deformation that did not induce any seismic events.

In addition to the potential to reactivate a fault several hundreds of meters away from the well, such a hydraulic connection could also significantly affect the flow conditions during the operation of a geothermal power plant. If fluid were extracted from the well, the produced fluid would mainly be governed by inflow from the most permeable structure, i.e., from the highly permeable fracture zone in our model. The porosity, which determines the amount of fluid contained in the rock, can be very low in fractured rock. Thus, if production targets such a fracture zone, high flow rates are unlikely to last long, which is consistent with the low flow rates measured during the production test in St. Gallen (Wolfgramm et al., 2015). In the case of a second well drilled for fluid production and using the first well for injection (i.e., a geothermal doublet), the injected fluid would flow rapidly out of the well into the hydraulic connection. Hence, the open section of the production well would need to intersect the fracture zone at another location to efficiently produce the injected fluid. In our model, a potential location of the production well could be close to the fracture zone/fault intersection. However, since the efficiency of a geothermal plant strongly depends on the temperature of the produced fluid (e.g., Schechinger and Kissling, 2015), which is a function of the residence time of the fluid in the reservoir, a single, highly permeable flow path between the production well and the injection well would be far from appropriate as the fluid could not heat up sufficiently and the efficiency of the geothermal plant would be low.

\subsection{Gas kick}

For the gas kick simulation, we follow the hypothesis that the seismicity caused by the initial stimulations breached a seal to an overpressurized gas reservoir. In order to initiate the kick, we assume a sudden large change in permeability (from $10^{-22}$ to $10^{-15} \mathrm{~m}^{2}$ ) in the fault core right below the caprock (at a depth of $4.5 \mathrm{~km}$ ). This enables the gas to pressurize the fracture zone and the bottom hole (i.e., the fracture zone/well intersection), where the pressure starts to increase after about $2 \mathrm{~h}$ (modeled curve in Fig. 8). We do not intend to completely fit the pressure curve measured in St. Gallen, because our high-permeability approach used for the well does not cover the physics of gas lifting, dynamic pressures, and pipe friction, which can play an important role during a kick (e.g., Pan et al., 2018). Instead, we focus on approximately matching the overpressure at the bottom hole and the timing of the gas kick. Since the pressure monitoring tool at the well bottom could not be retrieved after the gas kick and well control measures (Thomas Bloch, personal communication, 7 September 2019), we have to reconstruct the pres- sure change over time from the available wellhead pressure $P_{\text {wh }}$ and injection data. The gas kick occurred shortly after the release by the operating crew of some gas that had accumulated in the annulus ( $\Delta P \simeq 0.6 \mathrm{MPa}$ ). After closing the well, the pressure rapidly increased to $8 \mathrm{MPa}$, then slowly rose to about $9 \mathrm{MPa}$ (Fig. 8). At this point, the well was partially gas-filled and the weight of the fluid column was therefore below the hydrostatic equilibrium. During the injection of fresh water to combat the gas kick, the overpressure dropped to a plateau of $3 \mathrm{MPa}$ shortly after the amount of injected water corresponded to the volume of the borehole $\left(V_{\mathrm{bh}}=260 \mathrm{~m}^{3}\right.$; Fig. 8$)$. Subsequently, since continuing water injection would not reduce the pressure further, the borehole was probably almost completely water-filled again (i.e., in hydrostatic equilibrium). Therefore, the overpressure at the bottom hole caused by the gas may have approximately corresponded to the wellhead pressure of the plateau, i.e., about $3 \mathrm{MPa}$. Since we cannot rule out that the well was still partially filled with gas, this value is assumed to be a maximum overpressure that could have been caused by the gas. For the simulation, the bottom hole pressure reaches a steady plateau of ca. $2.4 \mathrm{MPa}$ after about $10 \mathrm{~h}$, which is similar to the value of the reconstructed bottom hole overpressure (note that injection is not modeled here). The well could finally be killed $\left(P_{\mathrm{wh}}=0\right)$ by the injection of dense $\left(\rho_{\mathrm{m}}=1320 \mathrm{~kg} \mathrm{~m}^{-3}\right) \mathrm{K}_{2} \mathrm{CO}_{3}$-based drilling fluid (Alber and Backers, 2015; Naef, 2015, and references therein). Assuming a fully fluid-filled borehole, a drilling mud injection volume of $V_{\mathrm{m}}=100 \mathrm{~m}^{3}$ (Alber and Backers, 2015, and references therein), and a water density of $\rho_{\mathrm{W}}=1000 \mathrm{~kg} \mathrm{~m}^{-3}$, the average fluid density can be calculated as

$\rho_{\text {avg }}=\frac{\left[V_{\mathrm{m}} \cdot \rho_{\mathrm{m}}+\left(V_{\mathrm{bh}}-V_{\mathrm{m}}\right) \cdot \rho_{\mathrm{w}}\right]}{V_{\mathrm{bh}}}=1123 \mathrm{~kg} \mathrm{~m}^{-3}$,

which results in a pressure of about $42 \mathrm{MPa}$ at a depth of $3.8 \mathrm{~km}$. This corresponds to an overpressure of approximately $5 \mathrm{MPa}$ with respect to the initial undisturbed reservoir pressure, which is indeed sufficient to prevent gas with an overpressure of $3 \mathrm{MPa}$ from entering the well.

The change in overpressure over time at the well bottom and the timing of the gas kick is dependent on different parameters such as the overpressure of the gas reservoir, the capillary pressure in the fault and in the fracture zone, and the permeability of the breached fault core. Here, we consider the effect of different permeabilities for the breached fault core, as this does not require reinitialization of the gas plume (Fig. 9). For the base case shown in Fig. 8, we set the permeability of the breached seal to $10^{-15} \mathrm{~m}^{2}$. Reducing the permeability by 1 order of magnitude leads to a significantly slower and weaker pressure response at the fracture zone/well intersection, whereas a 10-fold increase yields a similar overpressure as in the base case (Fig. 9a). In the latter case, the peak pressure is reached about $0.2 \mathrm{~d}$ before, followed by a pressure drop that is not observed for the base case. Similar to the permeability of the breached fault seal, we expect 


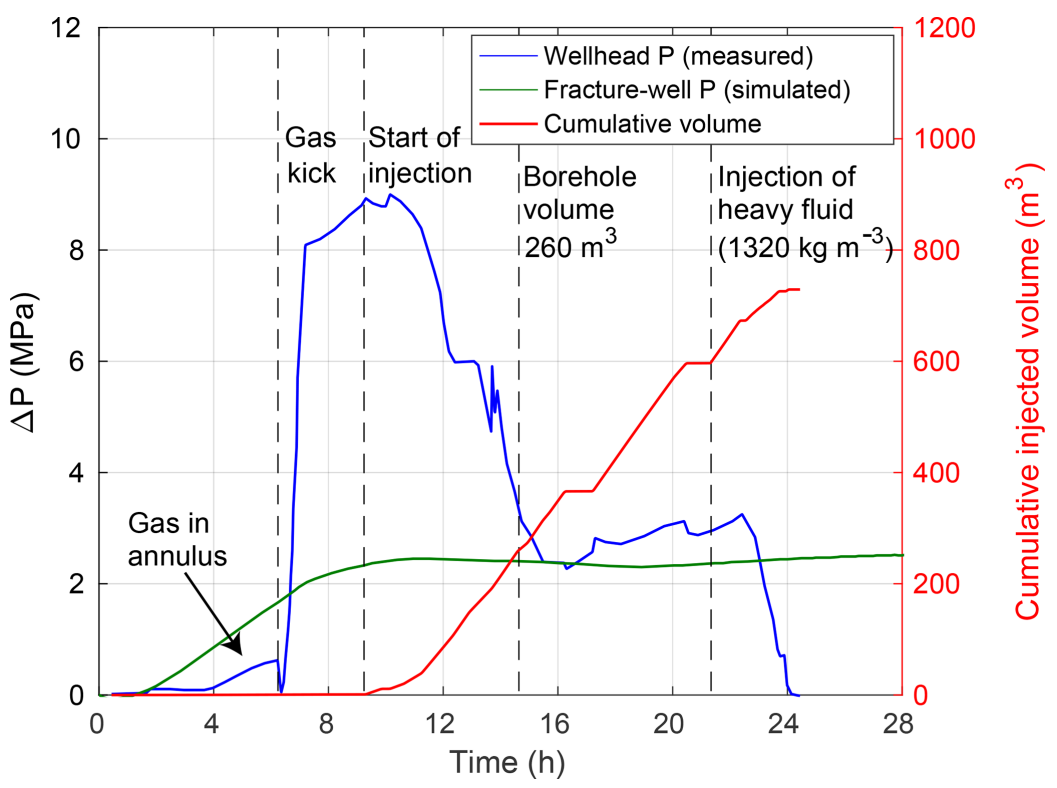

Figure 8. Measured wellhead pressure, simulated bottom hole pressure (fracture zone/well intersection inside fracture zone), and cumulative injected volume with time during the gas kick and well control injection. The vertical dashed black lines mark important events during the well operation (see text for more detailed explanations). The simulated overpressure at the bottom hole does not exceed the wellhead pressure prior to the injection of heavy fluids. Zero-time corresponds to the breach of the seal to initiate the gas kick in the simulation. Note that the injection is not modeled here.

the thickness of the fault core to influence the strength of the gas kick, because reducing the thickness would result in a higher pressure gradient between the two reservoir compartments, which would cause more fluid flow across the fault after the seal has been breached. In our numerical model, the thickness of $5 \mathrm{~m}$ corresponds to the width of the fault core elements. Individual fault cores are usually thinner than $1 \mathrm{~m}$ (e.g., Shipton et al., 2006), but faults may contain multiple narrow cores (e.g., Faulkner et al., 2010) so that the sealing part of the fault can be thicker, which can justify our assumption in the model. Moreover, note that according to Darcy's law, an increase (decrease) in permeability of the breached fault core would correspond to a decrease (increase) in thickness of the fault core, since in both cases the fluid flow across the fault would be equally affected. For instance, decreasing the fault core thickness by 1 order would correspond to the scenario with a breached-fault-seal permeability of $10^{-14} \mathrm{~m}^{2}$. Hence, the sensitivity study on the permeability of the breached fault seal is equivalent to examining the effect of fault core thickness on the strength of the gas kick. The permeability also has an effect on the timing of the gas kick, as illustrated in Fig. 9 b. In the case of $\kappa=10^{-14} \mathrm{~m}^{2}$, the gas reaches the fracture zone/well intersection after about $0.2 \mathrm{~d}$, whereas it takes 0.26 and $0.5 \mathrm{~d}$ for the cases of medium $\left(10^{-15} \mathrm{~m}^{2}\right)$ and low $\left(10^{-16} \mathrm{~m}^{2}\right)$ permeability, respectively. A second increase in gas saturation can be observed for the medium and high-permeability cases after about $0.8 \mathrm{~d}$, which occurs when the gas starts to accumulate in the upper part of the fracture zone between a depth of 3.6 and $3.8 \mathrm{~km}$. The change in pressure at the fracture zone/fault intersection that is located in the vicinity of the breached seal follows a similar trend when compared to the pressure simulated at the fracture zone/well intersection (Fig. 9c). Figure 9d shows the gas saturation of the base case at $y=0 \mathrm{~km}$ after $0.4 \mathrm{~d}$, i.e., about $3 \mathrm{~h}$ after the gas has reached the well. At this time, the entire fracture zone has a gas saturation of about $30 \%$.

\subsection{Well control injection and associated seismicity}

Starting from the same conditions as for the gas kick simulation (base case), we start to inject water after about $0.4 \mathrm{~d}$, i.e., about $3 \mathrm{~h}$ after the gas has reached the well - consistent with the observations illustrated in Fig. 8. We then follow the recorded injection protocol but ignore the injection of heavy mud at the end of the well control exercise. Using a total of 40000 seeds, we simulate 1000 realizations of the entire sequence for a simulation time of $10 \mathrm{~d}$. During the sequence, we assume further permeability changes in the fault core associated with the $M_{\mathrm{L}} 2.1$ and $M_{\mathrm{L}} 3.5$ events, the two largest earthquakes in the sequence. For the sake of simplicity, we set a permeability of $10^{-15} \mathrm{~m}^{2}$ after $0.9 \mathrm{~d}\left(M_{\mathrm{L}} 2.1\right)$ and $1.0 \mathrm{~d}\left(M_{\mathrm{L}} 3.5\right)$ on rectangular areas around the corresponding hypocenters that may have slipped (Fig. 10). Additionally, we account for the fact that the fracture zone/fault intersection has encountered some stress drop due to the seismicity induced by the previous activities (see Fig. 3) using a slightly higher criticality threshold in this region $\left(\mu_{\mathrm{c}}=0.015\right)$. 

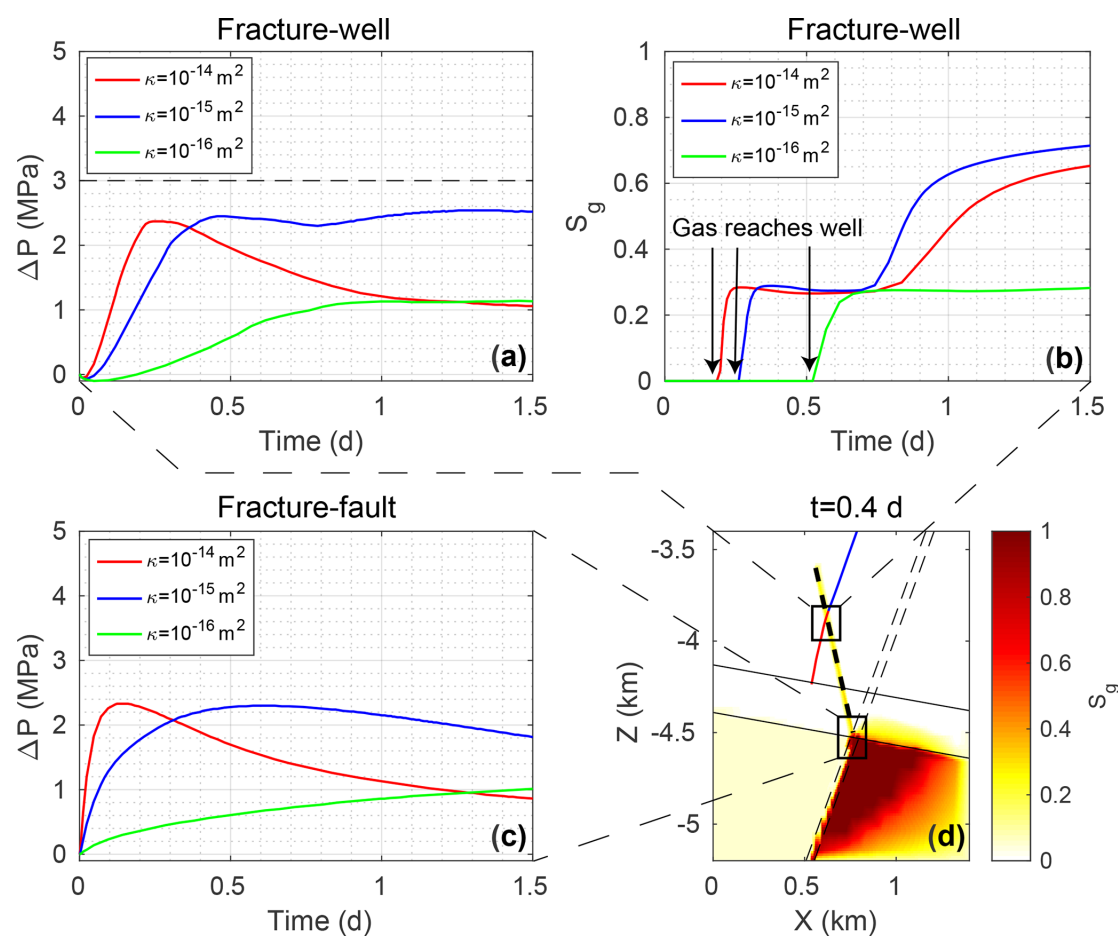

Figure 9. (a) Pressure change over time for different permeability values of the broken fault seal at the fracture zone/well intersection $(z \simeq-3.9 \mathrm{~km})$. The dashed black line at $3 \mathrm{MPa}$ marks the approximate pressure of the plateau in Fig. 8 , which is considered as a maximum overpressure that could have been caused by the gas (see text). Zero-time corresponds to the breach of the seal to initiate the gas kick. (b) Gas saturation over time for different permeability values of the broken fault seal at the fracture zone/well intersection $(z \simeq-3.9 \mathrm{~km})$. (c) Pressure change over time for different permeability values of the broken fault seal at the fracture zone/fault intersection $(z \simeq-4.5 \mathrm{~km}$, i.e., close to the breached seal). (d) Gas saturation after ca. $0.4 \mathrm{~d}$ at $y=0 \mathrm{~km}$ (normal to the fault, along profile A-A' in Fig. 2).

Figure 10 shows the pressure change on the left damage zone of the fault together with the simulated seismicity of a single model realization at different times. No seismicity is observed before the gas kick, whereas a few events are induced at a depth of about $4.6 \mathrm{~km}$ after the $M_{\mathrm{L}} 2.1$ and immediately before the $M_{\mathrm{L}} 3.5$ event (Fig. 10a, b, f and g). Shortly after the main shock (after $1 \mathrm{~d}$ ), seismicity has propagated further along the horizontal direction and to greater depth, mainly in regions where the permeability of the fault core has changed (Fig. 10c and h). During the following days, significantly more seismicity is induced, extending on a patch between a depth of 4.5 and $4.8 \mathrm{~km}$ and up to $0.5 \mathrm{~km}$ in the $y$ axis (Fig. 10d, e, i and j). Regarding the spatial distribution of the seismicity, our model approximately reproduces the extent of the observed seismicity cloud (Fig. 3e and f), although the simulated seismicity cloud is somewhat smaller than the observed one; the mean extent of the seismicity of the 1000 model realizations is $0.133 \mathrm{~km}^{2}$ with a standard deviation of $0.025 \mathrm{~km}^{2}$, while the area of the observed seismic events (with magnitudes greater than $M_{\mathrm{c}}$, see below) is $0.214 \mathrm{~km}^{2}$. The pressure is strongly affected by the permeability changes adopted in the model. The pressure in the left damage zone increases after the $M_{\mathrm{L}} 2.1$ event in the upper part of the fault (at a depth of approx. $4.6 \mathrm{~km}$ ) due to gas inflow, whereas the $M_{\mathrm{L}} 3.5$ event causes the pressure to decrease in the lower part of the rupture area because water flows across the fault (Fig. $10 \mathrm{~g}$ and $\mathrm{h}$ ). On the other hand, the pressure in the fault core increases after the main shock, which leads to the reactivation of seeds at greater depth (Fig. 10c). The negative change in pressure is compensated by water and gas inflow, and after $5 \mathrm{~d}$ the pressure change becomes positive along the entire fault (Fig. 10j).

With the given number of seeds, our model fits the temporal evolution of the seismicity (Fig. 11). Since the relocated catalog is incomplete for events with magnitudes $M_{\mathrm{c}}<0.8$, we only model events with $M_{\mathrm{w}} \geq M_{\mathrm{c}}$ in order to properly compare the data. We obtain a good match both for the number of events per time interval (Fig. 11a) and for the cumulative number of events (Fig. 11b). For the latter, the observations lie well within 1 standard deviation of the 1000 realizations of the seed model. Due to the permeability changes in the fault core associated with the two largest seismic events, the simulation captures the strong increase in seismicity after the main shock at about $1 \mathrm{~d}$. In order to quantify the influence of the gas on the seismicity, we introduce a criterion to assess whether the seeds were triggered by gas or water. We determine a seed to be gas-triggered if the change in gas saturation $\Delta S_{\mathrm{g}}$ with respect to the initial state is positive (i.e., $\Delta S_{\mathrm{g}}>0$ ), 

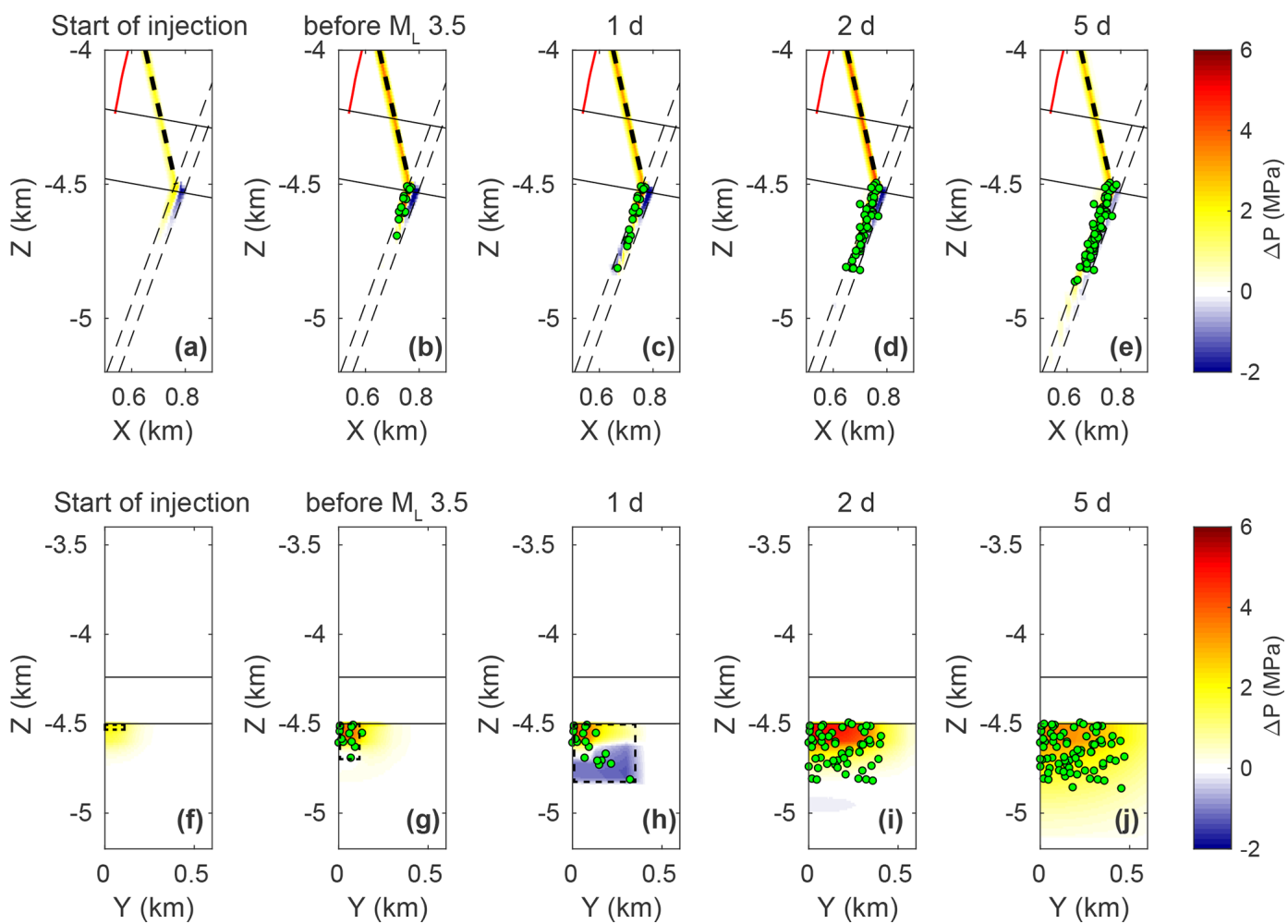

Figure 10. (a-e) Pressure change and simulated seismicity (single realization) during the gas kick and well control measures at $y=0 \mathrm{~km}$ after (a) ca. $0.4 \mathrm{~d}$ (start of injection), (b) $0.99 \mathrm{~d}$ (shortly before the $M_{\mathrm{L}} 3.5$ event), (c) $1 \mathrm{~d}$ (immediately after the $M_{\mathrm{L}} 3.5 \mathrm{event}$ ), (d) $2 \mathrm{~d}$, and (e) $5 \mathrm{~d}$ of simulation time along profile $\mathrm{A}-\mathrm{A}^{\prime}$ in Fig. 2 (normal to the fault). The open section of the well is denoted by the red line. The fault is illustrated by the thin dashed black lines, the fracture zone by the thick dashed black line, and the caprock by the solid black lines. (f-j) Pressure change and simulated seismicity (single realization) on the fault (left damage zone) after (f) approx. $0.4 \mathrm{~d}$ (start of injection), (g) $0.99 \mathrm{~d}$ (shortly before the $M_{\mathrm{L}} 3.5$ event), (h) $1 \mathrm{~d}$ (immediately after the $M_{\mathrm{L}} 3.5$ event), (i) $2 \mathrm{~d}$, and (j) $5 \mathrm{~d}$ of simulation time along profile $\mathrm{B}^{\prime}-\mathrm{B}$ in Fig. 2 (along fault). The solid black lines indicate the caprock. The dashed black rectangles denote the area of permeability change to (f) initiate the gas kick, due to (g) the $M_{\mathrm{L}} 2.1$ event, and because of (h) the $M_{\mathrm{L}} 3.5$ event.

which is equivalent to $\Delta P>\Delta P_{\mathrm{w}}$ and $\Delta P<\Delta P_{\mathrm{g}}$. A seed is also classified as gas-triggered if the region around it is fully gas saturated, and thus $\Delta S_{\mathrm{g}} \geq 0$. If seeds rupture due to static stress transfer, they are classified as neither gas- nor watertriggered. Figure $11 \mathrm{c}$ illustrates the gas-triggered events and the seeds reactivated by static stress transfer in comparison to the total number of events. On average, $39 \%$ of the seeds are triggered by the gas, while another $16 \%$ are triggered by the static stress transfer. Hence, a significant number of seeds are triggered by an increase in gas pressure. The influence of static stress interactions is more complex to assess, as triggered seeds may cause both negative (stress shadow) and positive Coulomb stress changes on adjacent seeds, bringing them closer or farther away from failure (Catalli et al., 2016; King et al., 1994). Hence, some seeds can be triggered by a change in fluid pressure (i.e., counted as gas or water-triggered) as a consequence of positive Coulomb stress change, while other seeds can be prevented from failure due to a negative change in the Coulomb stress, although they would have been triggered by fluid flow if stress transfer was ignored. An alternative approach to assess the influence of earthquake interaction is to run a model completely ignoring static stress transfer (Fig. 11d). The result shows that stress transfer starts to play an important role after about $1 \mathrm{~d}$ of simulation time (i.e., after the main shock). At the end of the simulation, disregarding stress transfer reduces the total number of triggered seeds by about $14 \%$ (note the difference of $2 \%$ to the approach above). Compared to the modeling results obtained for the EGS project in Basel, the influence of stress transfer is less but still of the same order (24\%; Catalli et al., 2016).

In our simulation, most of the seismicity is induced after the fault core breached during the two main events. In order to determine the effect of the gas and the well control injection on the induced seismicity without the a priori assumption of a breached fault seal, we consider scenarios where permeability is only changed to initiate the gas kick but not afterwards. In Fig. 12a, we plot the time of the first simulated earthquake (onset) for three different scenarios (1000 realizations each): (i) water injection according to the injection protocol of the well control measures, (ii) no injection, and (iii) opening the wellhead ( $\left.P_{\mathrm{wh}}=0.1 \mathrm{MPa}\right)$ and no injection. 

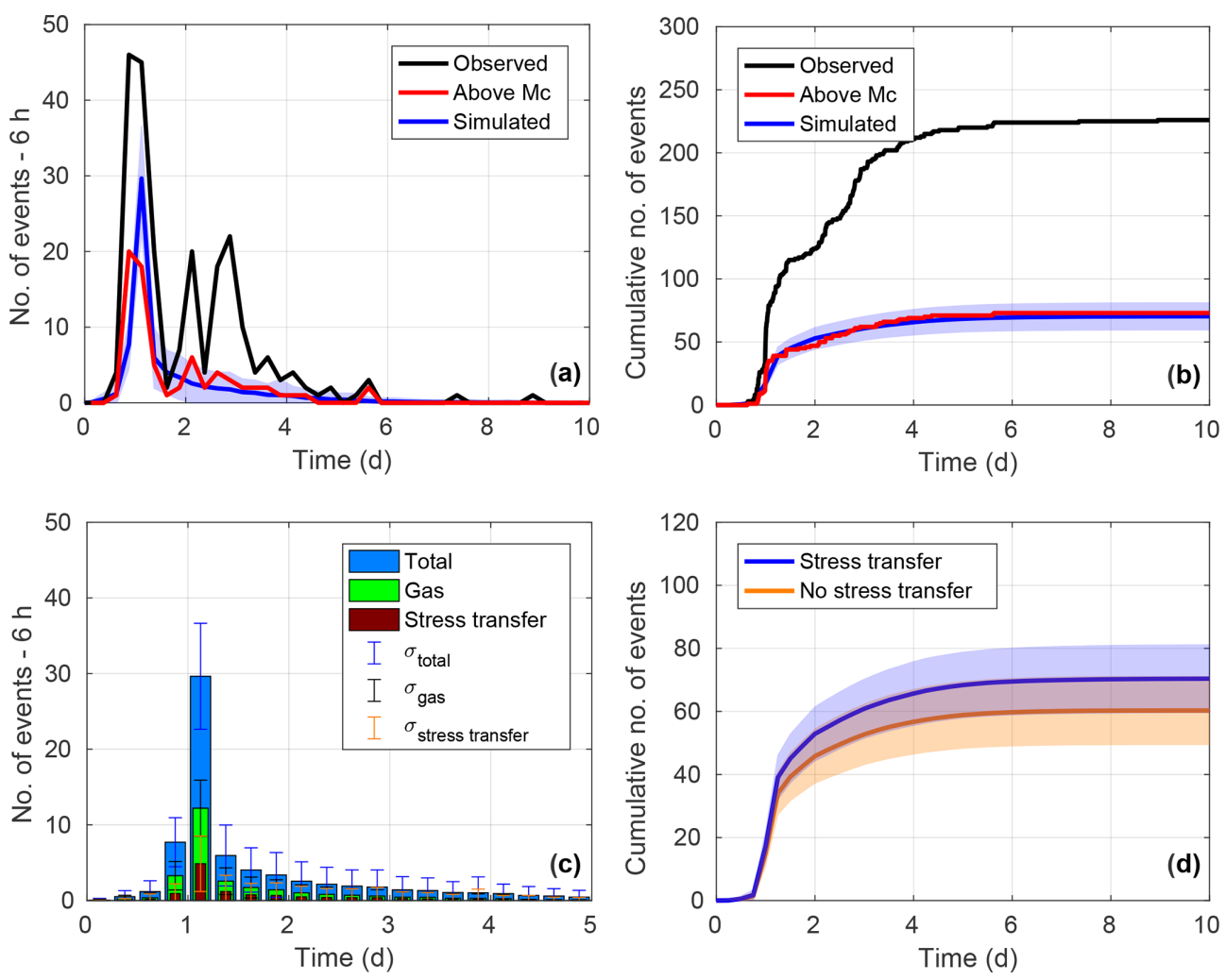

Figure 11. Statistical analysis of the main sequence simulation. (a) Number of events for every $6 \mathrm{~h}$ compared to the entire relocated catalog and events above $M_{\mathrm{c}}$. (b) Cumulative number of events with time compared to the entire relocated catalog and events above $M_{\mathrm{c}}$. (c) Number of events for every $6 \mathrm{~h}$ induced in total, by the gas and by static stress transfer. (d) Comparison of simulated cumulative number of events with and without stress transfer. The shaded area in (a), (b), and (d) and the error bars in (c) indicate 1 standard deviation over a total of 1000 realizations. Zero-time corresponds to the breach of the seal to initiate the gas kick.

In all three scenarios, the median onset of seismicity occurs a few hours after the time of the actual well control injection. The onset differs only slightly between the three scenarios ( 0.5 to $0.6 \mathrm{~d}$ ), whereas the uncertainty bars given by the first and third quartile show that the seismicity is increasingly delayed without water injection, particularly for the scenario with an open well, where the onset can become larger than $1 \mathrm{~d}$. For the scenarios without injection, in 77 and 96 (open well) realizations no seismicity is induced at all, whereas for the case of injection, in only 21 instances is seismicity absent. In the simulations, although the gas has to cross the fault to cause the gas kick in the well, seismicity does not start immediately after the fault seal breached. This occurs because a certain increase in pressure is required to reactivate even the most critically stressed seeds (because of the criticality threshold described in Sect. 4.1). The pressure change over time of the analyzed scenarios is shown in Fig. $12 \mathrm{~b}$ to d. The injection has a large effect at the fracture zone/well intersection, while it is less pronounced further away from the well. At the fracture zone/fault intersection and further down on the fault (at a depth of $4.6 \mathrm{~km}$ ), the additional pressure increase caused by the water injection is only a few tenths of a megapascal. This strong attenuation of the pressure response is mainly caused by the highly compressible gas in the fracture zone and in the fault that damps the effect of the injection. Opening the well merely has an effect at the fracture zone/well intersection, while no influence can be observed on the fault. Overall, the scenarios suggest that without injection, the seismicity is delayed but in most cases not absent, which is another indication that the gas significantly affected the induced seismicity. On average, only four events are induced for the injection case, whereas less than three events occur for the scenarios without injection. These small numbers roughly agree with the relocated catalog, where only seven events with a magnitude larger than $M_{\mathrm{c}}$ occurred before the $M_{\mathrm{L}} 2.1$ event.

\subsection{Effect of the gas on the induced seismicity}

Our simulations suggest that overpressurized gas played an important role during the St. Gallen induced seismicity sequence. Using our definition of gas-triggered events, the simulation that includes permeability changes due to the two main events shows that about $40 \%$ of the seeds were reactivated by the presence of the gas. Note that seeds are triggered not only directly by an increase in gas pressure but also indi- 

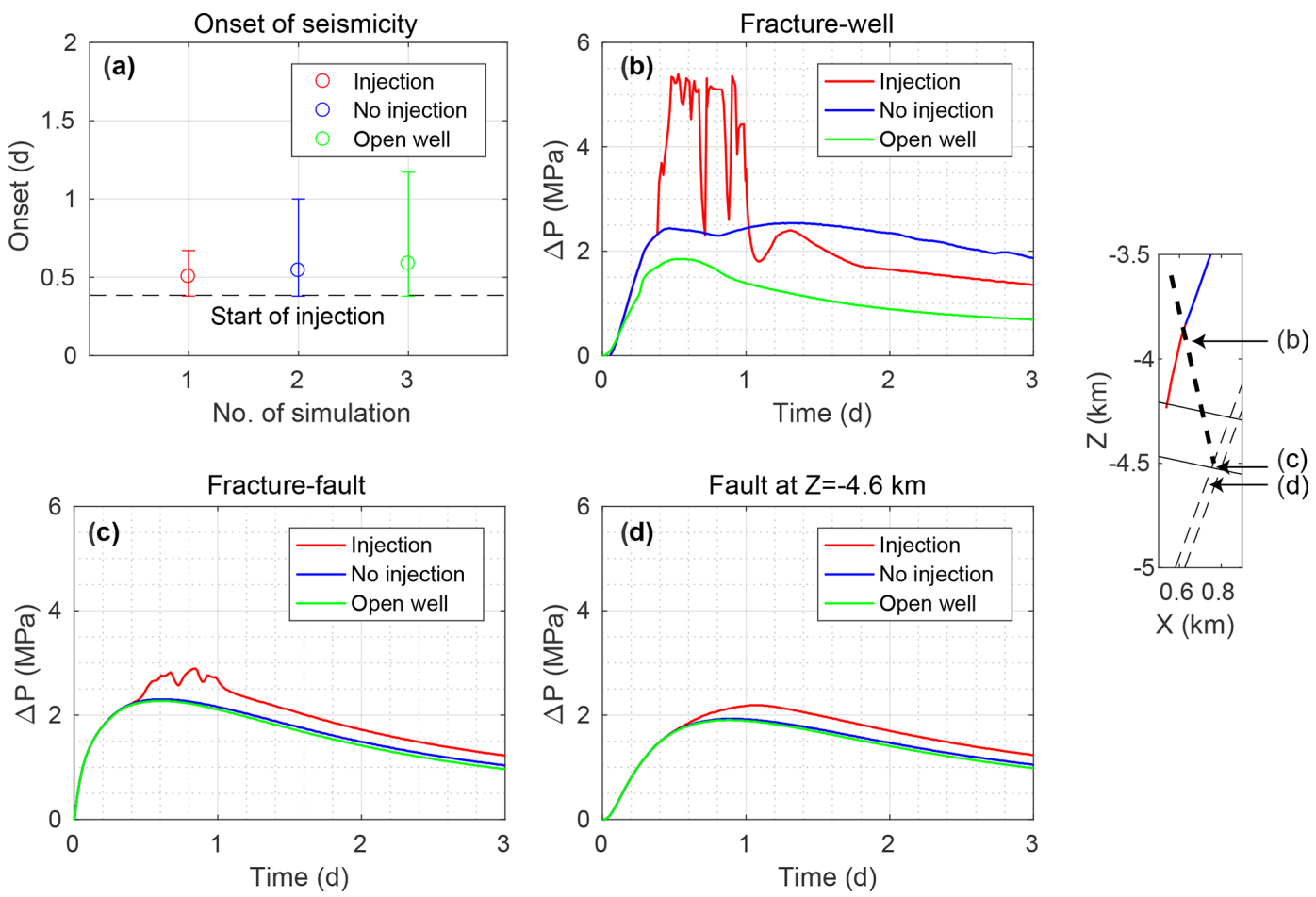

Figure 12. Comparison of scenarios with injection, without injection, and with an open well and no injection (1000 realizations each). (a) Onset of seismicity with error bars showing the first and third quartile around the median. The dashed line indicates the start of injection (ca. 0.4 d). (b-d) Pressure change at (b) the fracture zone/well intersection, (c) the fracture zone/fault intersection, and (d) within the fault at a depth of $4.6 \mathrm{~km}$. The model sketch on the right shows the locations of the pressure monitoring points.

rectly by gas that dissipates the water, which can pressurize more distant regions with unchanged gas saturation. On the other hand, the observed absence of seismicity in the beginning of the gas kick could be seen as an indicator that the gas did not directly affect the induced seismicity. However, our simulation can reproduce the delay of the onset of the seismicity (Fig. 12a) even though the gas has to cross the fault to initiate the gas kick. A delay of about $6 \mathrm{~h}$ was observed between the onset of the seismicity and the start of the well control injection, as opposed to the injection test where seismicity begins after $1 \mathrm{~h}$. Hence, the reason for the delay could be that the part of the fault that was pressurized first had been reactivated by the previous stimulations and was thus not as critically stressed (as assumed in our model). In the simulation, most of the seismicity occurs after a hydraulic connection between the left and right fault damage zones has been established, implying that these events are induced by multiphase fluid flow caused by the strong pressure gradient between the two compartments. Indeed, simulations ignoring further permeability changes (Fig. 12) produced significantly less events. Thus, in terms of seismicity, the simulation of the main sequence (Figs. 10 and 11) including the permeability changes in the two main events corresponds to a worst-case scenario with overpressurized gas. These results are supported by a maximum loss of waveform coherence in the ambient seismic noise field that was observed prior to the main shock, indicating a significant medium change due to fluid flow and associated pore pressure changes possibly caused by overpressurized gas (Obermann et al., 2015). Nevertheless, since most events are induced after the main shock and thus after our assumption of increased fault core permeability, the effect of the gas on a larger event remains unclear. From a physics-based point of view, our results suggest that the additional pressure increase due to the $M_{\mathrm{L}} 2.1$ event could have promoted an even larger event, since overpressurized fluid can have a direct influence on the rupture area of induced earthquakes (Galis et al., 2017). Hence, overpressurized gas could explain the large magnitude of the main shock that exceeded the theoretical threshold of the expected maximum magnitude (McGarr, 2014). In this study, because of the random assignment of magnitudes in the model, we cannot further elaborate on this. A physics-based model accounting for multiphase fluid conditions and explicitly simulating fault rupture may address this open question (e.g., Zbinden et al., 2017, 2018).

The extensive permeability change assumed in this model refers to a breach of the fault seal, as suggested by other field and modeling studies (e.g., Lyon et al., 2005; Miller et al., 2004). Additionally, enhanced permeability can be caused by shear dilation of pre-existing fractures (e.g., Lee and Cho, 2002; Rinaldi and Rutqvist, 2019). The sudden change in the hydraulic properties and associated fluid flow can explain the 
aftershock sequence of the $M_{\mathrm{L}} 3.5$ event. Such permeability changes in sealing faults due to induced seismicity can have implications for other geo-energy applications, such as $\mathrm{CO}_{2}$ sequestration and UGS. For instance, the large Hutubi underground gas storage (HUGS) facility in northwestern China is bound by multiple faults sealing the reservoir (e.g., Jiang et al., 2020). These seals may be damaged by small induced earthquakes reported in the field (Zhou et al., 2019), which could cause gas leakage. In addition to fluid flow, another important mechanism for aftershocks is static stress transfer, which can lead to stress redistribution around the sliding surface of the main shock, leading to further seismicity (Catalli et al., 2016; King and Devès, 2015). In our simulations, the contribution of static stress transfer is smaller than the influence of the gas (Fig. 11). Király-Proag et al. (2019) have recently analyzed the slip pattern of the main shock by back-projecting relative source time functions of the main events onto the reactivated fault plane. They found that most aftershocks that occurred within $5 \mathrm{~d}$ after the main shock are located at the edge of the $M_{\mathrm{L}} 3.5$ slip area, suggesting that stress concentration due to stress transfer may have played a major role. Here, with the exception of the assumed permeability changes, we do not explicitly model the main event with the associated stress drop and stress redistribution. Moreover, we treat fault strength as a static parameter excluding time-dependent failure caused by static stress transfer. Thus, a detailed geomechanical modeling of the $M_{\mathrm{L}} 3.5$ event that accounts for time-dependent failure is required to more accurately quantify the relative contribution of static stress transfer and fluid flow to the aftershock sequence.

The suggested model depends largely upon the initial conditions with a compartmentalized gas reservoir. To further investigate the effect of this assumption, we performed simulations with a model without a fault seal, where the gas reservoir equally pressurizes the left and right damage zones of the fault (Fig. 13a). In contrast to the case with a sealed fault, in the scenario without a fault seal the gas kick is initiated after a caprock seal breaks at the fracture zone/fault intersection. The results show that the gas kick at the bottom hole is stronger for the unsealed fault (Fig. 13b), because the gas plume is initially located slightly closer to the fracture zone, and the gas does not need to penetrate the broken fault seal (Fig. 13c), which has a 10-fold lower permeability than the rest of the fault. Hence, the gas reaches the well about $0.2 \mathrm{~d}$ (approx. $5 \mathrm{~h}$ ) earlier compared to the scenario that includes a fault seal (Fig. 13d). Note that the injection is started $3 \mathrm{~h}$ after the gas kick and thus not simultaneously for the two scenarios. A comparison of the pressure change at the left damage zone of the fault (at a depth of $4.6 \mathrm{~km}$ ) shows that the scenarios are inherently different. For the case of a sealing fault core, the pressure increases shortly after the gas kick is initiated, because the overpressurized gas intrudes into a previously undisturbed region (i.e., $P$ close to hydrostatic, $S_{\mathrm{g}} \simeq 0.1$. For the case without a seal, the pressure is affected neither by the gas kick nor by the fluid in- jection, because the fault is fully gas-filled $\left(S_{\mathrm{g}}=1\right)$ and already in an overpressurized condition. Hence, the pressure is largely unaffected during the gas kick, whereas during the injection, the gas is compressed with almost no effect on the pressure. Due to the near-zero pressure changes, we did not perform simulations with the seed model. The comparison shows that the scenario with a sealing fault and sudden permeability changes can more accurately describe the seismicity observed in St. Gallen. Nevertheless, the scenario with an unsealed fault also shows that gas does not necessarily enhance the seismicity, as it can damp the effect of the fluid injection.

Another possible explanation for the seismicity would be purely poroelastic stress changes without any hydraulic connection. In such a case, it was shown that stress changes on the fault are much smaller than in the case of a hydraulic connection (Zbinden et al., 2020), implying that the fault needs to be in a highly critical stress state (i.e., only a few $10^{-3} \mathrm{MPa}$ or less away from failure). In addition to the reasons already provided for the injection test, the following observations would be inconsistent with a poroelastic scenario.

1. Since there is no connection, the gas would probably be stored in the Malm layer or in the Upper Dogger in the vicinity of the well (e.g., Wolfgramm et al., 2015), which raises the question of why the gas did not enter the well during drilling or shortly after the injection test/acid stimulations.

2. The fault is oriented at an angle of about $50^{\circ}$ with respect to the maximum principal stress. According to the Mohr-Coulomb theory, an optimally oriented fault would exhibit an angle of $30^{\circ}$ (assuming $\mu_{\mathrm{s}}=0.6$ ). Hence, the fault in St. Gallen may not be that critically stressed.

3. The seismicity of the post-injection period (September to October 2013) shows diffusion-like propagation characteristics (Diehl et al., 2017) commonly observed for fluid flow.

For these reasons, we did not attempt a model simulation that accounted for poroelastic stress changes. Due to the complex interaction of multiphase fluid flow and seismicity at St. Gallen, we cannot rule out the possibility that the gas was stored at a different location and was therefore not directly linked to the seismicity. For instance, the gas could have been stored halfway between the well and the fault, implying that the gas would not directly pressurize the fault during the gas kick. Still, the scenario simulated here is the most likely from our point of view.

\subsection{Implications for future deep hydrothermal projects}

In Switzerland and elsewhere, target reservoirs for future hydrothermal projects may be located at a similar depth and in 

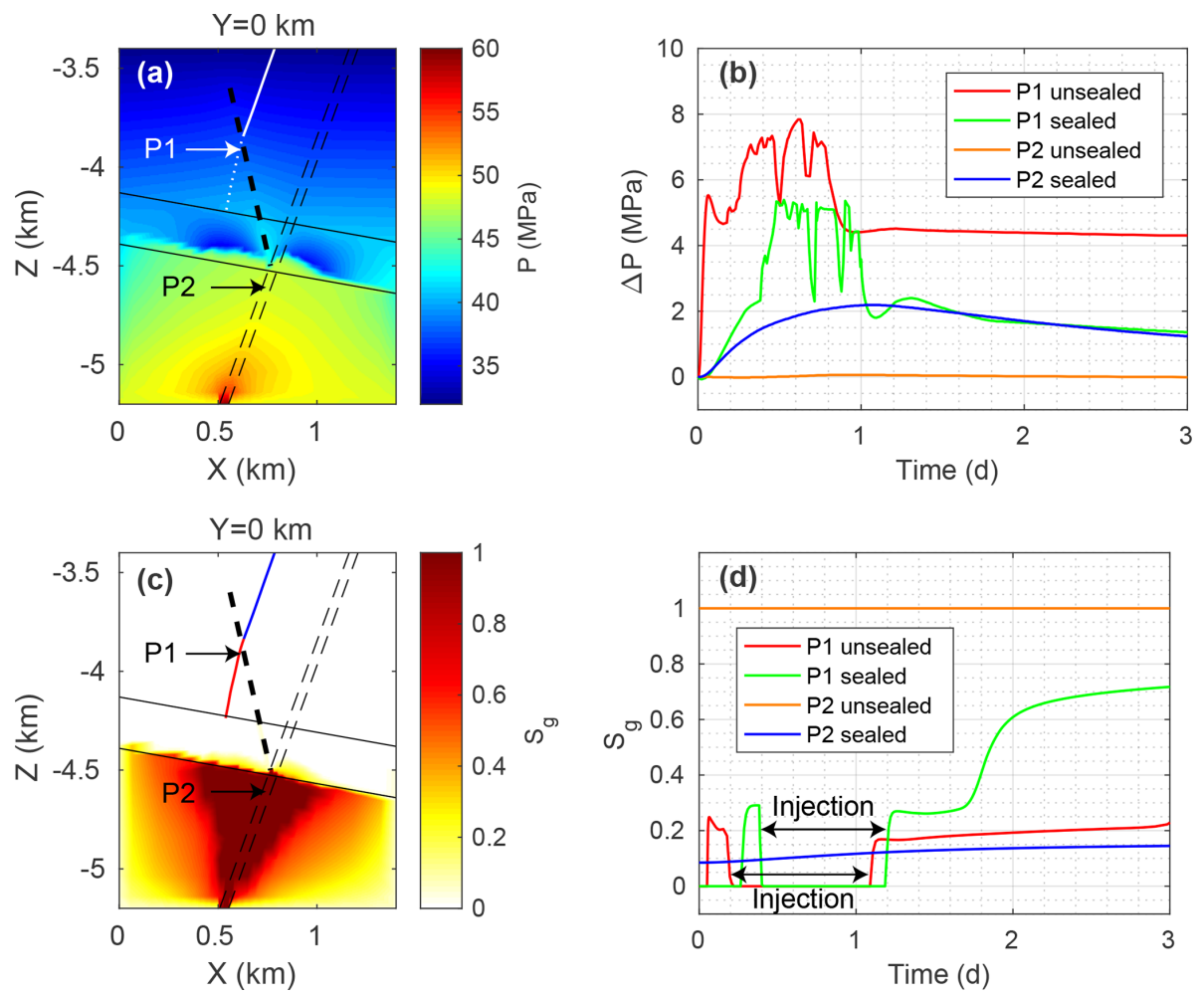

Figure 13. Scenario without a fault seal. (a) Initial pressure conditions at $y=0 \mathrm{~km}$ (along profile A-A', normal to the fault, in Fig. 2). The well is denoted by the dotted (open section) and solid (cased section) white line. (b) Pressure change with time at the fracture zone/well intersection and on the fault $(z=-4.6 \mathrm{~km})$ in comparison to the scenario with a sealing fault. (c) Initial gas saturation at $y=0 \mathrm{~km}($ along profile $\mathrm{A}-\mathrm{A}^{\prime}$ (normal to the fault) in Fig. 2). The well is denoted by the red (open section) and blue (cased section) lines. (d) Gas saturation over time at the fracture zone/well intersection and on the fault $(z=-4.6 \mathrm{~km})$ in comparison to the scenario with a sealing fault. (a, c) The fault is illustrated by the thin dashed black lines, the fracture zone by the thick dashed black line, and the caprock by the solid black lines.

similar geological conditions as the St. Gallen region. For instance, ongoing projects in the Western Alpine Molasse basin (WAMB) at the border between France and Switzerland aim to generate heat and electricity using the high geothermal potential of the area (Chelle-Michou et al., 2017). Due to the similar stratigraphy and the potential presence of PermoCarboniferous troughs serving as source rocks for gas, the probability of encountering gas during the drilling and stimulation of deep wells could be relatively high. The simulations of fault seal architecture (Fig. 13) indicate that the effect of gas on the induced seismicity highly depends on the location of the plume and the initial pressure and gas saturation of the fault. Although it is difficult to accurately evaluate potential locations of gas prior to any stimulation, the presence of a PCT can be a strong indication of gas and should be identified as early as possible in the project, for instance with an active 3D seismic survey (Heuberger et al., 2016) and gravimetric methods (e.g., Altwegg et al., 2015) as was done in the St. Gallen region. Furthermore, if natural gas is expected to be present at the reservoir depth, it is important to record parameters such as multiphase flow rates in the well and bottom hole pressure during the entire project to enable a more accurate hydromechanical analysis in both real-time and retrospectively. In St. Gallen, pressure at the well bottom was recorded with a memory tool, which unfortunately could not be retrieved after the well control measures. With regard to fluid injection, although our simulations strongly suggest that the effect of the well control injection was damped by the compressible gas in the fracture zone and the fault (even in the scenario of a compartmentalized gas reservoir), uncontrolled injection in future projects may greatly increase seismicity and the likelihood of inducing a felt event and should therefore be avoided where possible. In St. Gallen, stopping the injection of the well control operation during the gas kick was not an option due to safety reasons at the drilling site.

The simulation of the injection test shows that a hydraulic connection can lead to rapid pressure changes several hundreds of meters away from the well. Since this can lead to problems in the efficient operation of a geothermal power plant (see Sect. 5.1), an option for future hydrothermal projects may for instance be to seal such permeable structures with hydraulic packers. This may provide more uniform flow during injection and production operations and may increase the residence time of injected fluids, meaning that they can be extracted at a higher temperature from a nearby production well. The installation of packers during the stimula- 
tion phase could also help to more locally (i.e, more accurately) characterize the hydraulic properties of the reservoir. Hydraulic testing of small intervals in the open section of the borehole (e.g., individual fractures and faults intersecting the borehole) could significantly improve hydromechanical analyses and would provide more detailed input data for numerical models. Although expensive, such a multistage approach was recently carried out in an EGS project in Finland (e.g., Kwiatek et al., 2019) and could potentially also be used for hydrothermal systems.

In St. Gallen, the seismicity ceased during a production test conducted in October 2013. While long-term fluid production from porous reservoirs may lead to compaction and induce seismicity on faults intersecting the reservoir (e.g., van Thienen-Visser and Breunese, 2015; Zbinden et al., 2017), in the short term, production associated with a decrease in pore pressure can increase the effective normal stress and thus stabilize faults close to the reservoir. Moreover, in the case of a fractured low-porosity reservoir like St. Gallen, poroelastic compaction effects may be much less pronounced (e.g., Moeck et al., 2015). Hence, an initial production phase prior to any fluid injection operation may be a strategy to reduce the potential for fault reactivation in such hydrothermal reservoirs.

Finally, since faults can act as conduits for hot fluids from greater depth and can cause positive temperature anomalies (e.g., Chelle-Michou et al., 2017), they are often considered beneficial for geothermal heat production. Such temperature anomalies can be enhanced if a PCT is present, as the rising fluids may form convective cells in the permeable sediments of the Permo-Carboniferous grabens (Chelle-Michou et al., 2017). Nevertheless, operators must be aware that drilling and injecting into fault zones is always associated with a high probability of inducing felt seismicity, especially in the case of overpressurized gas as shown by the project in St. Gallen.

\section{Conclusions}

We have performed a detailed hydromechanical analysis of the multiphase fluid processes and the induced seismicity at the St. Gallen deep geothermal project with the following results:

1. Based on borehole logs, a seismic survey, and the earthquake catalog, we have developed a conceptual model that suggests a highly permeable connection between the injection well and the reactivated fault that is located at several hundreds of meters distance from the well.

2. We implement our concept in a numerical model that is calibrated against the measured well pressure of the injection test. The model shows that the small fluid volumes of the injection test $\left(175 \mathrm{~m}^{3}\right)$ are sufficient to yield a fast and significant pressure increase on the fault $(\Delta P \simeq 0.8 \mathrm{MPa}$ within $1 \mathrm{~h})$.
3. We simulate the gas kick using the calibrated model and assuming an overpressurized gas reservoir laterally sealed by the fault and released due to the stimulations. The model reproduces the reconstructed overpressure at the bottom hole during the gas kick $(\Delta P \simeq 3 \mathrm{MPa}$ ).

4. We are able to reproduce the temporal and spatial evolution of the main seismicity sequence following the well control injection. In order to match the aftershock sequence of the $M_{\mathrm{L}} 3.5$ event, we assume that the fault core is breached during the two largest events of the sequence, which results in strong pressure gradients and associated multiphase fluid flow.

5. The simulations show that the gas may have played a major role: based on the assumption of a breached fault and the initial conditions in our model, ca. $40 \%$ of the events were directly induced by the gas, while $16 \%$ were triggered by static stress transfer. Moreover, simulations without an injection delayed the onset of seismicity but in most cases still induced seismic events. Whether the gas increased the probability of inducing a larger event remains unclear and a more physics-based model regarding fault rupture could provide an answer.

6. In prospect of future deep hydrothermal projects, an initial phase of fluid production could stabilize faults in the vicinity of the reservoir and thus reduce the potential for fault reactivation. Additionally, since highly permeable fractures intersecting the borehole could become problematic during the long-term operation of a project in terms of heat exchange between the injected fluids and the reservoir rock, hydraulic packers could be used to seal such fractures and thus achieve more uniform flow behavior. Also, prior knowledge of the location of potential source rocks for gas (e.g., PCT) may help to better assess the hazards not only for gas kicks but also for induced seismicity. A 3D seismic survey in combination with other methods (e.g., gravimetric data), as carried out in the St. Gallen area, is therefore strongly recommended prior to any deep hydrothermal project.

Data availability. All model output data are available through the ETH repository https://doi.org/10.3929/ethz-b-000369225 (Zbinden, 2019). The catalog of the induced seismicity in St. Gallen can be found in the supporting information of Diehl et al. (2017). Injection and pressure data of the injection test are presented in Alber and Backers (2015) and references therein and can be requested from St. Galler Stadtwerke. Stress data are presented in Moeck et al. (2015) and can be requested from St. Galler Stadtwerke and Inga Moeck at the Leibniz Institute for Applied Geophysics (LIAG) in Hanover, Germany. 
Author contributions. DZ and APR conceptualized the model. DZ processed the model code and performed the numerical simulations. DZ prepared the paper with contributions from all coauthors.

Competing interests. The authors declare that they have no conflict of interest.

Acknowledgements. We thank Thomas Bloch from St. Galler Stadtwerke (sgsw) for his valuable comments that greatly improved the paper and for the permission to use the pressure and injection data as well as supporting documents. We are grateful to Toni Kraft from the Swiss Seismological Service (SED) for his useful comments during the preparation of this paper and for his support in collaborating with sgsw. We would like to thank Inga Moeck at the Leibniz Institute for Applied Geophysics (LIAG) in Hanover, Germany, for providing estimations on the in situ state of stress. We are also grateful to two anonymous reviewers and to the editors Tarje Nissen-Meyer and CharLotte Krawczyk for the useful comments and suggestions.

Financial support. This research has been supported by the Swiss National Science Foundation (grant no. PZENP2_160555).

Review statement. This paper was edited by Tarje Nissen-Meyer and reviewed by two anonymous referees.

\section{References}

Alber, M. and Backers, T.: Erforschung der Mechanismen und Simulation hydraulisch induzierter Risse in geklüfteten Gesteinen für die Optimierung des Aufschlusses geothermischer Lagerstätten, Abschlussbericht zum Verbundprojekt, geomecon $\mathrm{GmbH}$, Berlin, Germany, available at: http://www.gmg.ruhr-uni-bochum.de/mam/content/ ingenieurgeologie/schlussbericht_bmu_rub_geomecon_ fkz0325279_a_b_public.pdf (last access: 15 May 2020), 2015.

Altwegg, P., Schill, E., Abdelfettah, Y., Radogna, P.-V., and Mauri, G.: Toward fracture porosity assessment by gravity forward modeling for geothermal exploration (Sankt Gallen, Switzerland), Geothermics, 57, 26-38, https://doi.org/10.1016/j.geothermics.2015.05.006, 2015.

Baisch, S., Rothert, E., Stang, H., Vörös, R., Koch, C., and McMahon, A.: Continued geothermal reservoir stimulation experiments in the cooper basin (Australia), Bull. Seismol. Soc. Am., 105, 198-209, https://doi.org/10.1785/0120140208, 2015.

Breede, K., Dzebisashvili, K., Liu, X., and Falcone, G.: A systematic review of enhanced (or engineered) geothermal systems: past, present and future, Geotherm. Energ., 1, 1-27, https://doi.org/10.1186/2195-9706-1-4, 2013.

Catalli, F., Rinaldi, A. P., Gischig, V., Nespoli, M., and Wiemer, S.: The importance of earthquake interactions for injectioninduced seismicity: Retrospective modeling of the Basel En- hanced Geothermal System, Geophys. Res. Lett., 43, 4992-4999, https://doi.org/10.1002/2016GL068932, 2016.

Chang, K. and Segall, P.: Injection-induced seismicity on basement faults including poroelastic stressing, J. Geophys. Res.-Sol. Ea., 121, 2708-2726, https://doi.org/10.1002/2015JB012561, 2016.

Chelle-Michou, C., Do Couto, D., Moscariello, A., Renard, P., and Rusillon, E.: Geothermal state of the deep Western Alpine Molasse Basin, France-Switzerland, Geothermics, 67, 48-65, https://doi.org/10.1016/j.geothermics.2017.01.004, 2017.

Corey, A. T.: The interrelation between gas and oil relative permeabilities, Produc. Mon., 19, 38-41, 1954.

Diehl, T., Clinton, J., Kraft, T., Husen, S., Plenkers, K., Guilhelm, A., Behr, Y., Cauzzi, C., Kästli, P., Haslinger, F., Fäh, D., Michel, C., and Wiemer, S.: Earthquakes in Switzerland and surrounding regions during 2013, Swiss J. Geosci., 107, 359-375, https://doi.org/10.1007/s00015-014-0171-y, 2014.

Diehl, T., Kraft, T., Kissling, E., and Wiemer, S.: The induced earthquake sequence related to the St. Gallen deep geothermal project (Switzerland): Fault reactivation and fluid interactions imaged by microseismicity, J. Geophys. Res.-Sol. Ea., 122, 7272-7290, https://doi.org/10.1002/2017JB014473, 2017.

Edwards, B., Kraft, T., Cauzzi, C., Kästli, P., and Wiemer, S.: Seismic monitoring and analysis of deep geothermal projects in st Gallen and Basel, Switzerland, Geophys. J. Int., 201, 1022-1039, https://doi.org/10.1093/gji/ggv059, 2015.

Ellsworth, W. L.: Injection-induced earthquakes, Science, 341, 1225942, https://doi.org/10.1126/science.1225942, 2013.

Ellsworth, W. L., Giardini, D., Townend, J., Ge, S., and Shimamoto, T.: Triggering of the Pohang, Korea, Earthquake $\left(M_{\mathrm{W}} 5.5\right)$ by Enhanced Geothermal System Stimulation, Seismol. Res. Lett., 90, 1844-1858, https://doi.org/10.1785/0220190102, 2019.

Evans, K. F., Zappone, A., Kraft, T., Deichmann, N., and Moia, F.: A survey of the induced seismic responses to fluid injection in geothermal and $\mathrm{CO}_{2}$ reservoirs in Europe, Geothermics, 41, 30 54, 2012.

Fäh, D., Giardini, D., Kästli, P., Deichmann, N., Gisler, M., Schwarz-Zanetti, G., Alvarez-Rubio, S., Sellami, S., Edwards, B., Allmann, B., Bethmann, F., Wössner, J., Gassner-Stamm, G., Fritsche, S., and Eberhard, D.: ECOS-09 earthquake catalogue of Switzerland release 2011 report and database, Public catalogue, 17.4.2011, Swiss Seismological Service ETH Zurich, Report SED/RISK/R/001/20110417, 2011.

Faulkner, D. R., Jackson, C. A., Lunn, R. J., Schlische, R. W., Shipton, Z. K., Wibberley, C. A., and Withjack, M. O.: A review of recent developments concerning the structure, mechanics and fluid flow properties of fault zones, J. Struc. Geol., 32, 1557-1575, https://doi.org/10.1016/j.jsg.2010.06.009, 2010.

Finsterle, S. and Zhang, Y.: Solving iTOUGH2 simulation and optimization problems using the PEST protocol, Environ. Model. Softw., 26, 959-968, https://doi.org/10.1016/j.envsoft.2011.02.008, 2011.

Foulger, G. R., Wilson, M. P., Gluyas, J. G., Julian, B. R., and Davies, R. J.: Global review of humaninduced earthquakes, Earth-Sci. Rev., 178, 438-514, https://doi.org/10.1016/j.earscirev.2017.07.008, 2018.

Galis, M., Ampuero, J. P., Mai, P. M., and Cappa, F.: Induced seismicity provides insight into why earthquake ruptures stop, Sci. Adv., 3, eaap7528, https://doi.org/10.1126/sciadv.aap7528, 2017. 
Ghassemi, A. and Tao, Q.: Thermo-poroelastic effects on reservoir seismicity and permeability change, Geothermics, 63, 210-224, https://doi.org/10.1016/j.geothermics.2016.02.006, 2016.

Giardini, D.: Geothermal quake risks must be faced, Nature, 462, 848-849, https://doi.org/10.1038/462848a, 2009.

Gischig, V. and Wiemer, S.: A stochastic model for induced seismicity based on non-linear pressure diffusion and irreversible permeability enhancement, Geophys. J. Int., 194, 1229-1249, https://doi.org/10.1093/gji/ggt164, 2013.

Gischig, V., Wiemer, S., and Alcolea, A.: Balancing reservoir creation and seismic hazard in enhanced geothermal systems, Geophys. J. Int., 198, 1585-1598, https://doi.org/10.1093/gji/ggu221, 2014.

Goebel, T. H. and Brodsky, E. E.: The spatial footprint of injection wells in a global compilation of induced earthquake sequences, Science, 361, 899-904, https://doi.org/10.1126/science.aat5449, 2018.

Goertz-Allmann, B. P. and Wiemer, S.: Geomechanical modeling of induced seismicity source parameters and implications for seismic hazard assessment, Geophysics, 78, KS25-KS39, https://doi.org/10.1190/geo2012-0102.1, 2013.

Grigoli, F., Cesca, S., Priolo, E., Rinaldi, A. P., Clinton, J. F., Stabile, T. A., Dost, B., Fernandez, M. G., Wiemer, S., and Dahm, T.: Current challenges in monitoring, discrimination, and management of induced seismicity related to underground industrial activities: A European perspective, Rev. Geophys., 55, 310-340, https://doi.org/10.1002/2016RG000542, 2017.

Grigoli, F., Cesca, S., Rinaldi, A., Manconi, A., López-Comino, J., Clinton, J., Westaway, R., Cauzzi, C., Dahm, T., and Wiemer, S.: The November $2017 M_{\mathrm{W}} 5.5$ Pohang earthquake: A possible case of induced seismicity in South Korea, Science, 360, 1003-1006, https://doi.org/10.1126/science.aat2010, 2018.

Hergert, T., Heidbach, O., Reiter, K., Giger, S. B., and Marschall, P.: Stress field sensitivity analysis in a sedimentary sequence of the Alpine foreland, northern Switzerland, Solid Earth, 6, 533-552, https://doi.org/10.5194/se-6-533-2015, 2015.

Heuberger, S., Roth, P., Zingg, O., Naef, H., and Meier, B. P.: The St. Gallen Fault Zone: a long-lived, multiphase structure in the North Alpine Foreland Basin revealed by 3D seismic data, Swiss J. Geosci., 109, 83-102, https://doi.org/10.1007/s00015016-0208-5, 2016.

Hirschberg, S., Wiemer, S., and Burgherr, P., eds.: Energy from the Earth: Deep Geothermal as a Resource for the Future?, vdf Hochschulverlag, Zürich, Switzerland, 1, 1-447, https://doi.org/10.3218/3655-8, 2015.

Hopp, C., Sewell, S., Mroczek, S., Savage, M., and Townend, J.: Seismic response to injection well stimulation in a hightemperature, high-permeability reservoir, Geochem. Geophy. Geosy., 20, 2848-2871, https://doi.org/10.1029/2019GC008243, 2019.

Jeanne, P., Rutqvist, J., Rinaldi, A. P., Dobson, P. F., Walters, M., Hartline, C., and Garcia, J.: Seismic and aseismic deformations and impact on reservoir permeability: The case of EGS stimulation at The Geysers, California, USA, J. Geophys. Res.-Sol. Ea., 120, 7863-7882, https://doi.org/10.1002/2015JB012142, 2015.

Jiang, G., Qiao, X., Wang, X., Lu, R., Liu, L., Yang, H., Su, Y., Song, L., Wang, B., and fong Wong, T.: GPS observed horizontal ground extension at the Hutubi (China) underground gas storage facility and its application to geomechanical modeling for induced seismicity, Earth Planet. Sc. Lett., 530, 115943, https://doi.org/10.1016/j.epsl.2019.115943, 2020.

Kastrup, U., Zoback, M. L., Deichmann, N., Evans, K. F., Giardini, D., and Michael, A. J.: Stress field variations in the Swiss Alps and the northern Alpine foreland derived from inversion of fault plane solutions, J. Geophys. Res.-Sol. Ea., 109, 1-22, https://doi.org/10.1029/2003JB002550, 2004.

Kim, J., Tchelepi, H. A., and Juanes, R.: Rigorous coupling of geomechanics and multiphase flow with strong capillarity, Soc. Petrol. Engin. J., 18, 1123-1139, https://doi.org/10.2118/141268-PA, 2013.

Kim, K. H., Ree, J. H., Kim, Y. H., Kim, S., Kang, S. Y., and Seo, W.: Assessing whether the $2017 M_{\mathrm{W}} 5.4$ Pohang earthquake in South Korea was an induced event, Science, 360, 1007-1009, https://doi.org/10.1126/science.aat6081, 2018.

King, G. and Devès, M.: Fault Interaction, Earthquake Stress Changes, and the Evolution of Seismicity, Elsevier, 2nd Edn., 4, 243-271, https://doi.org/10.1016/B978-0-444-53802-4.00077-4, 2015.

King, G. C., Stein, R. S., and Lin, J.: Static stress changes and the triggering of earthquakes, Bull. Seismol. Soc. Am., 84, 935-953, 1994.

Király-Proag, E., Satriano, C., Bernard, P., and Wiemer, S.: Rupture process of the $M_{\mathrm{W}} 3.3$ earthquake in the St. Gallen 2013 geothermal reservoir, Switzerland, Geophys. Res. Lett., 46, 7990-7999, https://doi.org/10.1029/2019GL082911, 2019.

Kraft, T., Mai, P. M., Wiemer, S., Deichmann, N., Ripperger, J., Kästli, P., Bachmann, C., Fäh, D., Wössner, J., and Giardini, D.: Enhanced geothermal systems: Mitigating risk in urban areas, EOS T. Am. Geophys. Un., 90, 273-274, https://doi.org/10.1029/2009EO320001, 2009.

Kwiatek, G., Saarno, T., Ader, T., Bluemle, F., Bohnhoff, M., Chendorain, M., Dresen, G., Heikkinen, P., Kukkonen, I., Leary, P., Leonhardt, M., Malin, P., Martínez-Garzón, P., Passmore, K., Passmore, P., Valenzuela, S., and Wollin, C.: Controlling fluid-induced seismicity during a 6.1-km-deep geothermal stimulation in Finland, Sci. Adv., 5, eaav7224, https://doi.org/10.1126/sciadv.aav7224, 2019.

Lee, H. S. and Cho, T. F.: Hydraulic characteristics of rough fractures in linear flow under normal and shear load, Rock Mech. Rock Eng., 35, 299-318, https://doi.org/10.1007/s00603-0020028-y, 2002.

Lee, K.-K., Ellsworth, W. L., Giardini, D., Townend, J., Ge, S., Shimamoto, T., Yeo, I.-W., Kang, T.-S., Rhie, J., Sheen, D.-H., Chang, C., Woo, J.-U., and Langenbruch, C.: Managing injection-induced seismic risks, Science, 364, 730-732, https://doi.org/10.1126/science.aax1878, 2019.

Lyon, P. J., Boult, P. J., Hillis, R. R., and Mildren, S. D.: Sealing by shale gouge and subsequent seal breach by reactivation: A case study of the Zema Prospect, Otway Basin, AAPG Hedberg Series, 2nd Edn., 179-197, 2005.

Marzocchi, W. and Sandri, L.: A review and new insights on the estimation of the b-value and its uncertainty, Ann. Geophys., 46, 1271-1282, 2003.

McGarr, A.: Maximum magnitude earthquakes induced by fluid injection, J. Geophys. Res.-Sol. Ea., 119, 1008-1019, https://doi.org/10.1002/2013JB010597, 2014. 
Miller, S. A., Collettini, C., Chiaraluce, L., Cocco, M., Barchi, M., and Kaus, B. J. P.: Aftershocks driven by a high-pressure $\mathrm{CO}_{2}$ source at depth, Nature, 427, 724-727, 2004.

Moeck, I. S., Bloch, T., Graf, R., Heuberger, S., Kuhn, P., Naef, H., Sonderegger, M., Uhlig, S., and Wolfgramm, M.: The St. Gallen project: development of fault controlled geothermal systems in urban areas, in: Proceedings World Geothermal Congress, Melbourne, Australia, 19-25 April, 2015.

Naef, H.: Die Geothermie-Tiefbohrung St. Gallen GT-1, Berichte der St. Gall. Naturw. Gesell., 92, 359-392, 2015.

Nasrifar, K. and Bolland, O.: Prediction of thermodynamic properties of natural gas mixtures using 10 equations of state including a new cubic two-constant equation of state, J. Petrol. Sci. Eng., 51, 253-266, https://doi.org/10.1016/j.petrol.2006.01.004, 2006.

Obermann, A., Kraft, T., Larose, E., and Wiemer, S.: Potential of ambient seismic noise techniques to monitor the St. Gallen geothermal site ( Switzerland ), J. Geophys. Res.-Sol. Ea., 120, 1-16, https://doi.org/10.1002/2014JB011817, 2015.

Pan, L., Oldenburg, C. M., Freifeld, B. M., and Jordan, P. D.: Modeling the Aliso Canyon underground gas storage well blowout and kill operations using the coupled wellreservoir simulator T2Well, J. Petrol. Sci. Eng., 161, 158-174, https://doi.org/10.1016/j.petrol.2017.11.066, 2018.

Pruess, K., Oldenburg, C., and Moridis, G.: TOUGH2 User's Guide, Version 2.1, Paper lbnl-43134 (revised), Lawrence Berkeley National Laboratory, Berkeley, CA, USA, 2012.

Rinaldi, A., Rutqvist, J., Sonnenthal, E., and Cladouhos, T.: Coupled THM modeling of hydroshearing stimulation in tight fractured volcanic rock, Transport in Porous Media, 108, 131-150, https://doi.org/10.1007/s11242-014-0296-5, 2015.

Rinaldi, A. P. and Nespoli, M.: TOUGH2-seed: A coupled fluid flow and mechanical-stochastic approach to model injection-induced seismicity, Comput. Geosci., 108, 86-97, https://doi.org/10.1016/j.cageo.2016.12.003, 2017.

Rinaldi, A. P. and Rutqvist, J.: Joint opening or hydroshearing? Analyzing a fracture zone stimulation at Fenton Hill, Geothermics, 77, 83-98, https://doi.org/10.1016/j.geothermics.2018.08.006, 2019.

Rinaldi, A. P., Rutqvist, J., Finsterle, S., and Liu, H. H.: Inverse modeling of ground surface uplift and pressure with iTOUGH-PEST and TOUGH-FLAC: The case of $\mathrm{CO}_{2}$ injection at In Salah, Algeria, Comput. Geosci., 108, 98-109, https://doi.org/10.1016/j.cageo.2016.10.009, 2017.

Rutqvist, J.: Fractured rock stress-permeability relationships from in situ data and effects of temperature and chemical-mechanical couplings, Geofluids, 15, 48-66, https://doi.org/10.1111/gfl.12089, 2015.

Schechinger, B. and Kissling, E.: Energy from the Earth: Deep Geothermal as a Resource for the Future?, chap. WP1, Resources, 25-50, https://doi.org/10.3218/3655-8, 2015.

Shipton, Z. K., Soden, A. M., Kirkpatrick, J. D., Bright, A. M., and Lunn, R. J.: How Thick is a Fault? Fault Displacement-Thickness Scaling Revisited, American Geophysical Union (AGU), 170, 193-198, https://doi.org/10.1029/170GM19, 2006.
Terzaghi, K. V.: Die Berechnug der Durchlässigkeitsziffer des Tones aus dem Verlauf der hydromechanischen Spannungserscheinungen, Sitzungsber. Akad. Wiss. Wien., Math.-Naturwiss. Kl., Abt. 2A, 132, 125-138, 1923.

van Genuchten, M. T.: A Closed-form Equation for Predicting the Hydraulic Conductivity of Unsaturated Soils, Soil Sci. Soc. Am., 44, 892-898, https://doi.org/10.2136/sssaj1980.03615995004400050002x, 1980.

van Thienen-Visser, K. and Breunese, J.: Induced seismicity of the Groningen gas field: History and recent developments, Leading Edge, 34, 664-671, https://doi.org/10.1190/tle34060664.1, 2015.

Witherspoon, P. A., Wang, J. S., Iwai, K., and Gale, J. E.: Validity of cubic law for fluid flow in a deformable rock fracture, Water Resour. Res., 16, 1016-1024, https://doi.org/10.1029/WR016i006p01016, 1980.

Wolfgramm, M., Bloch, T., Bartels, J., Heuberger, S., Kuhn, P., Naef, H., Seibt, P., Sonderegger, M., Steiger, T., and Uhlig, S.: Reservoir-geological characterization of a fractured limestone : Results obtained from the geothermal well St. Gallen GT1 (Switzerland), in: Proceedings World Geothermal Congress, Melbourne, Australia, 19-25 April, 2015.

Yeck, W. L., Hayes, G. P., McNamara, D. E., Rubinstein, J. L., Barnhart, W. D., Earle, P. S., and Benz, H. M.: Oklahoma experiences largest earthquake during ongoing regional wastewater injection hazard mitigation efforts, Geophys. Res. Lett., 44, 711717, https://doi.org/10.1002/2016GL071685, 2017.

Zbinden, D.: Modeling output data used in publication "Potential influence of overpressurized gas on the induced seismicity in the St. Gallen deep geothermal project (Switzerland)", ETH Zurich, https://doi.org/10.3929/ethz-b-000369225, 2019.

Zbinden, D., Rinaldi, A. P., Urpi, L., and Wiemer, S.: On the physics-based processes behind production-induced seismicity in natural gas fields, J. Geophys. Res.-Sol. Ea., 122, 3792-3812, https://doi.org/10.1002/2017JB014003, 2017.

Zbinden, D., Rinaldi, A. P., and Wiemer, S.: Modeling the effect of a gas phase during injection-induced fault reactivation, in: TOUGH Symposium 2018, 1-4, Lawrence Berkeley National Laboratory, Berkeley, CA, USA, 2018.

Zbinden, D., Rinaldi, A. P., Diehl, T., and Wiemer, S.: Hydromechanical modeling of fault reactivation in the St. Gallen deep geothermal project (Switzerland): Poroelasticity or hydraulic connection?, Geophys. Res. Lett., 47, e2019GL085 201, https://doi.org/10.1029/2019GL085201, 2020.

Zhou, P., Yang, H., Wang, B., and Zhuang, J.: Seismological Investigations of Induced Earthquakes Near the Hutubi Underground Gas Storage Facility, J. Geophys. Res.-Sol. Ea., 124, 8753-8770, https://doi.org/10.1029/2019JB017360, 2019.

Zoback, M. D.: Reservoir Geomechanics, 154-158, Cambridge University Press, New York, 2010. 